\title{
Analysis of Federal Subsidies: Implied Price of Carbon
}

\section{Craig Cooper}

Thomas Foulke

October 2010

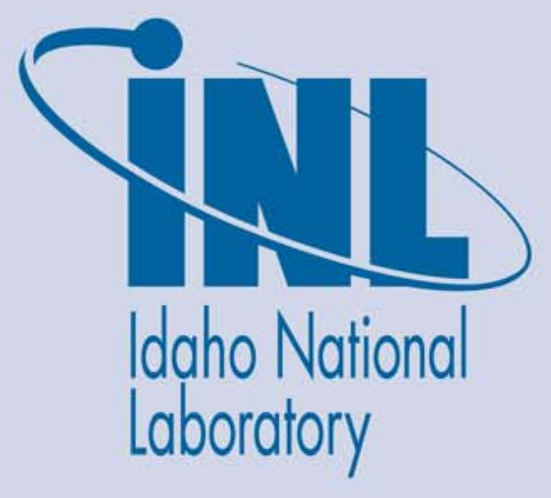

The INL is a U.S. Department of Energy National Laboratory operated by Battelle Energy Alliance 
INL/EXT-10-19340

Rev. 1

\title{
Analysis of Federal Subsidies: Implied Price of Carbon
}

\author{
Craig Cooper, Idaho National Laboratory \\ Thomas Foulke, University of Wyoming
}

October 2010

Idaho National Laboratory

Idaho Falls, Idaho 83415

http://www.inl.gov

Prepared for the

U.S. Department of Energy

Climate Change Technology Program

Under DOE Idaho Operations Office

Contract DE-AC07-05ID14517 


\section{Table of Contents}

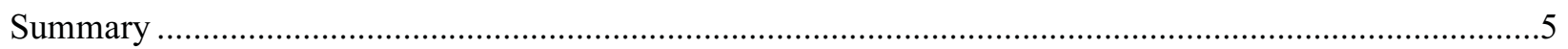

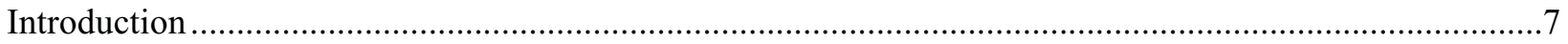

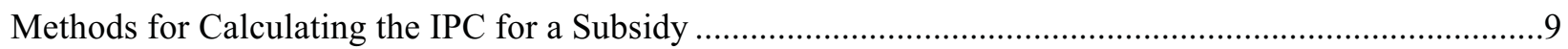

"Decision tree" for estimating the IPC of a subsidy or set of subsidies .........................................

Implications of the "decision tree" of determinations for estimating the IPC of a subsidy .............11

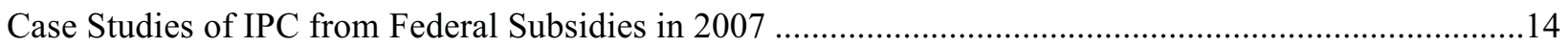

Case 1 - Fuel specific subsidies to electricity generation ......................................................14

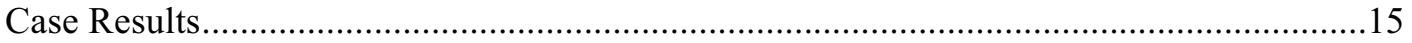

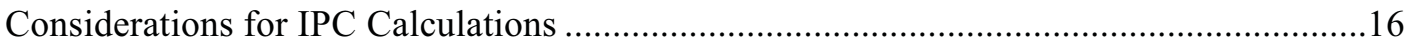

Implications of Case Results for Climate Policy.................................................................18

Case 2 - Support to renewable electricity from the New Technology Credit...............................19

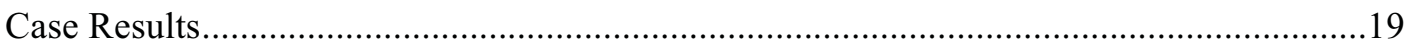

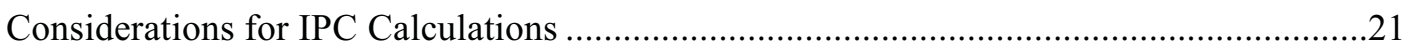

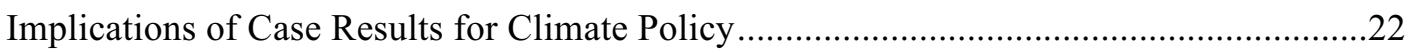

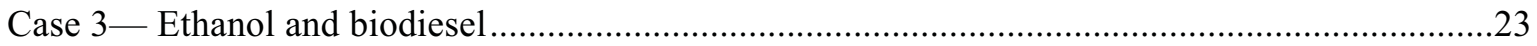

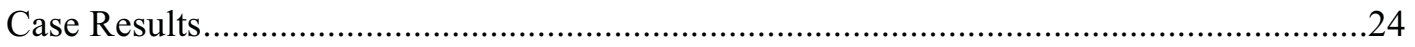

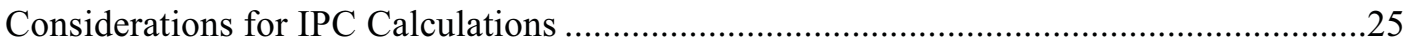

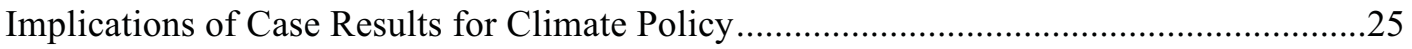

Case 4- Federal utilities and electricity support to rural utilities ............................................26

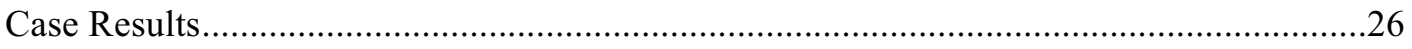

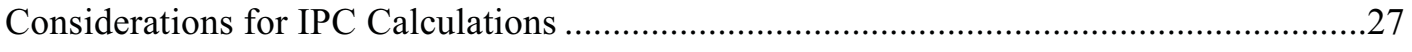

Implications of Case Results for Climate Policy .............................................................29

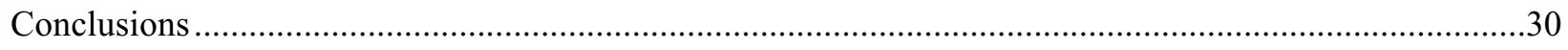

References

Appendix I - Summary of Policies Assessed in Case Studies ................................................................33

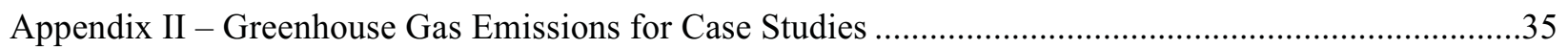

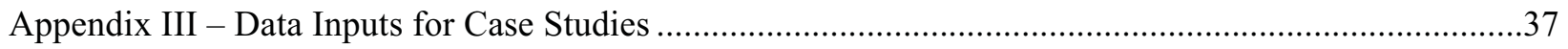

Appendix IV - Climate Change Technology Program, Static Implied Price Calculator; Concept and

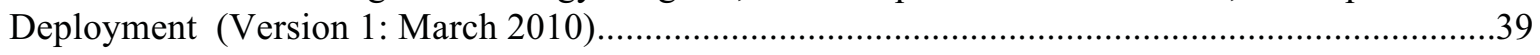




\section{Summary}

For informed climate change policy, it is important for decision makers to be able to assess how the costs and benefits of federal energy subsidies are distributed and to be able to have some measure to compare them. One way to do this is to evaluate the implied price of carbon (IPC) for a federal policy, or set of policies. For federal energy subsidies, which cost the U.S. Treasury nearly $\$ 17$ billion in 2007, the IPC can be defined as the cost of the subsidy to the U.S. Treasury divided by the emissions reductions it generated. Subsidies with lower IPC are more cost effective at reducing greenhouse gas emissions, while subsidies with a negative IPC act to increase emissions. While simple in concept, the IPC is difficult to calculate in practice. Calculation of the IPC requires knowledge of (i) the amount of energy associated with the subsidy, (ii) the amount and type of energy that would have been produced in the absence of the subsidy, and (iii) the greenhouse gas emissions associated with both the subsidized energy and the potential replacement energy. These pieces of information are not consistently available for federal subsidies, and there is considerable uncertainty in cases where the information is available. Thus, exact values for the IPC based upon fully consistent standards cannot easily be calculated with available data. However, it is possible to estimate a range of potential values sufficient for initial comparisons.

This study has developed and demonstrated a methodology to calculate first order estimates of the IPC of a range of federal subsidies using static methods that do not account for the dynamics of supply and demand. The IPC value depends upon how the inquiry is framed, and the IPC cannot be calculated in a "one size fits all" manner. IPC calculations can provide a valuable perspective for climate policy analysis. IPC values are most useful when calculated within the perspective of a case study, with the method and parameters of the calculation determined by the case. The IPC of different subsidies can then be quantitatively evaluated within the case. Results can be qualitatively compared across cases, so long as the limits of such comparisons are acknowledged and conclusions are treated with the appropriate degree of caution.

Results from four case studies indicate that the federal subsidies evaluated herein incentivize a range of behaviors that act to stimulate both greenhouse gas emissions reductions and increased emissions. For electricity production, analysis of total fuel-specific subsidies to electricity production (case \#1) indicate that the Alternative Fuel Production Credit has a negative IPC, effectively subsidizing increased emissions; and that subsidies to natural gas and nuclear electricity production may provide more cost effective emissions reductions than subsidies to renewable energy production. Analysis of the New Technology Credit for renewable electricity production (case \#2) reveals that the same subsidy yields different IPC's for different renewable generating technologies; and that the value of the IPC is dependent on whether the subsidy is assessed on a single-year basis or a project lifetime basis (e.g. lifetime of generating facility). Landfill gas has a higher IPC than wind and solar electricity on an annual basis (higher emissions), but a lower IPC on a lifetime basis (longer facility lifetime). Regardless of the term of evaluation, federal payments to hydroelectricity and biomass generation have the lowest IPC of all technologies supported by this subsidy. Federal support to power marketing administrations and rural utilities (case \#4) have the lowest IPC for low-carbon generation of any electricity subsidy evaluated. Together, these electricity analyses suggest that a low-carbon infrastructure investment subsidy based on historic experience with rural utilities and federal 
power marketing administrations may provide an effective way to reduce greenhouse gas emissions from the electric power sector.

For production of transportation fuels, IPC should be evaluated in the context of lifecycle emissions rather than the "simple emissions" (e.g. direct emissions) used for assessment of the IPC of subsidies to support electricity production. Evaluation of the subsidies to incentivize production of ethanol and biodiesel (case \#3) indicate that the IPC depends upon the method of converting feedstock into fuel. Subsidies to support production of corn ethanol from coal-heated refineries increase greenhouse gas emissions relative to California-grade gasoline. Support of corn ethanol production from natural gas and biomass heated refineries reduce greenhouse gas emissions, but at a cost in excess of $\$ 150$ per metric ton $\mathrm{CO}_{2} \mathrm{e}$. Biodiesel subsidies have an IPC lower than that of the Volumetric Ethanol Excise Tax (VEETC) for corn ethanol, but higher than what is projected if the VEETC is applied to the future production of cellulosic ethanol. Taken together, these fuel analyses suggest that current biofuels subsidies likely do not achieve the best possible greenhouse gas reductions per dollar cost to the U.S. Treasury.

Overall results from evaluation of the IPC for the four case studies presented herein indicate that federal energy subsidies are not well aligned with climate priorities and that the suite of federal subsidies needs to become more coherent if U.S. climate objectives are to be met in the most cost effective manner. Preliminary comparison of IPC calculations both within and across cases suggests that subsidies developed specifically to support renewable energy production may be more expensive and less effective from a climate perspective than subsidies to incentivize reduced greenhouse gas emissions, regardless of the energy feedstock. These results also suggest that subsidies to support construction of long-lasting, low-carbon energy generating infrastructure could be more cost effective than policies to promote production of a specific type of fuel on an annual basis. Historic policies that provide interest rate support to federal power marketing agencies and rural utilities provide an intriguing model to test. These entities provided over $40 \%$ of current U.S. renewable generating capacity and approximately $10 \%$ of U.S. nuclear capacity in 2007; and are supported by subsidies that have the lowest IPC of all subsidies investigated by this study. These entities are well integrated into the U.S. energy system; and have existing capability to accelerate energy technology deployment and may provide a model for enhancing U.S. efforts to reduce greenhouse gas emissions while sustaining economic growth through investments in low carbon energy infrastructure.

These conclusions are preliminary and need to be tested in follow-on analyses. Nevertheless, they are intriguing and challenge much of the current paradigm. Consequently, IPC analysis provides a useful perspective for climate policy and should become a standard method for climate policy evaluation. 


\section{Introduction}

A recent analysis by the Energy Information Administration indicates that the United States Treasury provided nearly $\$ 17$ billion/year in direct subsidies, tax credits, and other financial incentives to reduce greenhouse gas $(\mathrm{GHG})$ emissions and promote energy security goals in 2007; with nearly two-thirds of those subsidies classified as tax expenditures [1]. More recently, approximately $\$ 24.6$ billion in federal stimulus dollars are being invested in a range of clean energy and energy efficiency R\&D, demonstration, and deployment programs over a 2-year period (American Recovery and Reinvestment Act of 2009). This act also extended tax breaks for home energy efficiency, residential renewable energy, and hybrid electric vehicles.

Each of these subsidies has a unique history. They have been crafted by different Congresses and implemented by different administrations at different times, and reflect both the evolution and conflict of historic U.S. energy priorities. They also incur a cost on the U.S. Treasury. Clean energy and greenhouse gas emissions reductions are a relatively new priority in U.S. governance, and many of these subsidies predate the emergence of the national demand for clean energy. Thus, there is a need to evaluate these subsidies with respect to emerging new energy priorities and determine what adjustments could be made. Such an evaluation needs a basis of national value obtained for the federal cost. For climate policy, one potential measure of value is the implied price of carbon (IPC) of federal payments. For a federal payment (e.g. subsidy), the IPC is the cost of the subsidy to the U.S. Treasury divided by the emissions reductions it generated. Subsidies with lower IPCs are more cost effective at reducing greenhouse gas emissions, while subsidies with a negative IPC act to increase emissions. If the IPC for a subsidy is known, then multiple subsidies can be compared to help determine which combinations of technologies and subsidies can best advance climate policy objectives.

Calculation of the IPC for a subsidy requires knowledge of (i) the amount of energy associated with the subsidy, (ii) the amount and type of energy that would have been produced in the absence of the subsidy, and (iii) the greenhouse gas emissions associated with both the subsidized energy and the potential replacement energy. Calculating these values can be straightforward in cases where the subsidy is defined in terms of energy production per dollar of payment, the alternative energy sources are clear, and the greenhouse gas (GHG) emissions profiles of the respective energy technologies are well established. However, the process becomes uncertain in cases where these values are less well established. Furthermore, the information needed to calculate the IPC is not always available; or imprecise when it is available. Given this inherent variability and uncertainty, IPC cannot be calculated as a single value. Instead, it is a range of values that encompasses the energy choices that market actors can make.

IPC reflects the climate impact of decisions that the federal government makes in order to influence how energy markets respond to the combined impact of multiple market and nonmarket factors. The IPC is derived, in part, from predictions made by economic models used to predict the choices that energy markets make in response to subsidies and market conditions. IPC is not predictive of those dynamics. There are a number of models that can be used to estimate the variables used in an IPC calculation; (i) amount of energy subsidized, (ii) amount and type of "replacement energy" that would occur in the absence of the subsidy, and (iii) greenhouse gas emissions of subsidized and replacement energy. These different models will typically be based 
on different assumptions, use different parameters, and will consequently yield different absolute results. However, because IPC is a policy measure instead of an economic parameter, the purpose of the calculation is to facilitate subsidy comparison rather than to predict outcomes. Comparing relative values of the IPC of different subsidies is more important than calculating the absolute value. Consequently, the governing decision in developing and implementing a method of IPC calculation is to insure that the method is internally consistent - so that different subsidies can be reliably compared.

To be internally consistent, the method of IPC calculation needs to account for differences in subsidy structure. The method also must be internally consistent across multiple subsidy structures so that a set of subsidies that combine to promote a specific energy resource or energy service can be meaningfully compared. Thus, the IPC for a subsidy or set of subsidies must be calculated in a way that is specific to their structure, but general enough so that appropriate comparisons can be made. This is a problem of both computation (e.g. how the IPC is calculated) and classification (e.g. which IPC calculation should be apply). This type of internal consistency can be achieved with any modeling approach, but is easier to achieve with simpler models that have fewer parameters and clearer sets of underlying principles. To facilitate development of the IPC concept, this study seeks to minimize the number of assumptions that need to be made consistent across multiple policies by utilizing the simplest possible methods for IPC calculation. This will yield results that are preliminary in nature, but can be refined in future studies through via the use of more complex economic models.

This report presents a method for classifying federal energy subsidies, and then calculating the IPC for subsidies that have similar properties. The report also presents four case studies that estimate the IPC for selected subsidies, and discusses key issues arising from this assessment. The report is broken into four major sections: 1) introduction, 2) method for grouping subsidies and computing the IPC; 3) case studies of subsidy purpose and computed IPCs; and 4) summary of how the IPC's compare according to commonalities in energy resource and energy service subsidized. The summary discussion and recommendations section assess the results of the study in light of the primary objectives and provides recommendations for the path forward. The subsidies considered in the case studies are summarized in Appendix I. Greenhouse gas emissions data is provided in Appendix II, data inputs for case studies is provided in Appendix III, and a detailed discussion of how the calculations are structured is provided in Appendix IV. 


\section{Methods for Calculating the IPC for a Subsidy}

The common perception of an energy subsidy is that it is a federal payment for energy production, and that the payment is linked to the production of every unit of energy supported by the subsidy. While some subsidies are structured in this way, this is not the case for all subsidies and there are many different ways in which a subsidy supports energy production. These differences in subsidy structure must be taken into account when assessing the cost to the U.S. government of reducing GHG emissions. Developing a general framework that defines the steps that must be taken while allowing flexibility in how to apply these steps to different groups of subsidies can achieve this goal. Calculating an IPC using such a framework involves five steps.

1. Determine the energy service, or combination of services impacted by the subsidy (e.g. electricity, heat, transportation fuel).

2. Estimate the amount and type of energy production impacted by the subsidy.

3. Estimate the amount and type of energy "replaced" (i.e. energy that would have been generated in the absence of the subsidy).

4. Estimate the emissions associated with both the subsidized energy resource and the replacement energy.

5. Calculate IPC: IPC = subsidy cost / (emissions from alternative "replacement" energy emissions from subsidized energy). This is the subsidy cost divided by the net reductions in emissions attributable to the subsidy.

"Replacement" energy is the energy that would have been extracted, generated, or used in the absence of the subsidy, and is dependent upon the combination of energy resources and energy services that the subsidy supports. For example, the replacement energy for a renewable electricity production credit would be electricity generated from another resource (e.g. nuclear, coal, natural gas). The replacement energy for a coal subsidy would be a mixture of other electricity sources used to replace the coal used to produce electricity and alternative heat sources used to replace coal used for process heating.

\section{"Decision tree" for estimating the IPC of a subsidy or set of subsidies}

The method for evaluating IPC according to the five steps enumerated above depends on the structure of the subsidy in question, and the method of calculating emissions. Determining how to estimate these values involves a minimum of five determinations. These determinations, which control how the IPC is calculated, are:

1. Determine the energy service supported by the subsidy (e.g. electricity, process/space heating, transportation fuels).

2. Determine what energy resource is subsidized and what resources could have replaced the subsidized fuel in the absence of the subsidy.

3. Determine whether the subsidy is valued in terms of subsidy per unit energy generated, or whether the subsidy alters energy production in a non-specific way that is not directly 
linked to energy production. If non-specific, then the amount of energy impacted must be estimated.

4. Determine whether the subsidy's costs and impacts are limited to a single year, or whether the costs and impacts extend over multiple years.

5. Determine whether to use simple emissions or lifecycle emissions when calculating IPC.

- Simple emissions are those that result from converting an energy resource into an energy service, for example coal combustion to produce electricity.

- Lifecycle emissions are those that result from the entire lifecycle of resource extraction, conversion, use, and waste disposal. Lifecycle emissions are dependent on how the system is defined.

This decision tree, as it applies to U.S. energy production since 1999, has been coded into a set of Excel spreadsheets that are termed the "IPC Calculator". This calculator is the basis for all IPC values reported herein. Due to gaps in available information, only case studies for 2007 are presented in this study. Details of how to use the IPC calculator as it is currently structured are provided in Appendix IV. A general overview is provided here.

An underlying principle of all decision trees encoded within the IPC calculator is that no model or set of assumptions can adequately capture the complexity of the impact of subsidies on U.S. energy markets. Consequently, the amount and type of energy that would have been produced in the absence of a subsidy is inherently unknowable - and dependent upon how the analysis is framed. The IPC calculator conducts the analysis according to a set of principles that produce a first order estimate of the IPC, based on the above decision tree. These principles are:

- All calculations are static, and assume that energy production subsidies impact energy resource selection, but do not alter total consumption of energy services.

- Only subsidies that directly influence energy production and can be attributed to a definable amount of energy generation can be assessed. This is a subset of total subsidies, and explicitly excludes R\&D subsidies.

- Energy production data and energy subsidy data are gathered from reports and on-line databases produced by the U.S. DOE Energy Information agency (EIA). Multiple data resources are used, and references are given in the Appendices.

- Replacement energy is defined as the energy that would have been produced in the absence of the subsidy. The analyst selects a potential replacement fuel, and the IPC is calculated specifically in terms of a switch between the subsidized resource and the assumed replacement fuel.

- $\quad$ GHG emissions are calculated directly from energy generation using emissions factors provided by EIA. For cases where EIA does not provide emissions factors, best estimates have been gathered from peer-reviewed literature and government reports. Multiple data resources are used, and references are given in Appendix II.

- Direct emissions are used to estimate the IPC for the heat and electricity production. Multiple data resources are used, and references are given in Appendix II. 
- Lifecycle emissions derived from the GREET model are used to estimate the IPC for production of transportation fuels. Multiple data resources are used, and references are given in Appendix II.

In closing, it is important to note that this "decision tree" method for estimating the potential range of IPC's for a subsidy is probably the simplest method that can be used, and requires the fewest parameters. Other options would include the computation of the levelized cost of energy (LCOE), which is an economic assessment of the entire cost of energy generation over an energy-generating system's lifetime. LCOE methodology requires a greater number of modeling parameters in order to conduct an analysis, and thus the LCOE method is not employed in this study.

\section{Implications of the "decision tree" of determinations for estimating the IPC of a subsidy}

The five-step decision tree discussed in the previous section carries with it a number of implications associated with each decision. These are discussed here, in the order of determinations that must be made. The first determination regards the type of energy service that the IPC will be calculated for. The IPC calculator considers five energy services; (i) electricity, (ii) heat, (iii) transportation, (iv) electrical transmission, and (v) fuel distribution. If the fuel being subsidized can support multiple energy services, then the IPC only applies the subsidy payment to the proportion of the subsidized fuel that EIA reports was directed to the energy service in the year in question.

The determination of the energy service limits the range of energy resources that can be considered as a subsidized fuel and replacement fuel in the second determination. In the simplest formulation (employed herein), electricity cannot provide industrial process heating or transportation; and motor gasoline cannot provide electricity. This approach simplifies the calculation method, but carries some limitations. In reality, electricity can be used for process heating (e.g. smelting), and transportation fuels can be used to power an electric generator. The use of energy services as the first step in the decision tree calculation limits the ability of an analyst to account for these considerations. The benefit of this limitation is that it also limits the number of assumptions an analyst must make.

Once the service is established, the analyst makes a second determination to select the energy resource subsidized and the replacement fuel. These determinations then establish the energy difference associated with the subsidy. The emissions difference is calculated from the energy difference using parameters defined in the fifth step.

The third determination sets how the subsidy is valued. If the subsidy has an explicit dollar amount per unit energy, such as a payment per kilowatt-hour of electricity produced or a payment per gallon of fuel mixed, then the method calculates the total subsidy value from total energy generated. In this case, the amount of replacement fuel that would have been used in the absence of the subsidy is equal to the entire amount of subsidized energy. If the subsidy does not have a fixed payment per unit energy produced, then the analyst must estimate a proportion of the total energy that would be replaced by a different resource in the absence of the subsidy. A large subsidy might impact $100 \%$ of resource generation, while a small subsidy might have a 
minimal impact. For example, Figure 1 examines how the IPC could change depending upon the amount of electricity that might have switched to the U.S. grid average in the absence of subsidies specific to coal-, gas-, nuclear-, and renewable electricity generation when total tax subsidies that supported these electricity sources in 2007 are taken into account. The subsidy values are "total tax expenditures" as reported by EIA [1]. The IPC is calculated by dividing these subsidies by the emissions difference that would result if total electrical generation from a given resource in 2007 (e.g. coal, natural gas, nuclear, renewable) were replaced by U.S. grid average electricity. Coal subsidies, which increase emissions per kilowatt-hour, have a negative IPC (i.e., coal subsidies incentivize higher emissions). All other generating resources have lower emissions per kilowatt-hour than U.S. grid average and have a positive IPC (e.g. incentivized reduced emissions). The IPC decreases exponentially as the amount of energy production impacted by the subsidy increases, until stabilizing above $50 \%$ replacement. This is logical, as the IPC will be lower the more emissions it reduces per dollar of expenditure from the U.S. Treasury. The range of possible IPC values is enormous for cases when the payment per-unit energy is not directly specified, and this creates considerable uncertainty when trying to estimate IPC for a subsidy that does not have an explicit, statutory payment per unit energy. IPC analyses need to account for this consideration, either in calculation structure or in evaluating the implications of an IPC analysis.

\section{Percent of Subsidized Generation Replaced by U.S. Grid Average Electricity in the Absence of a Subsidy}

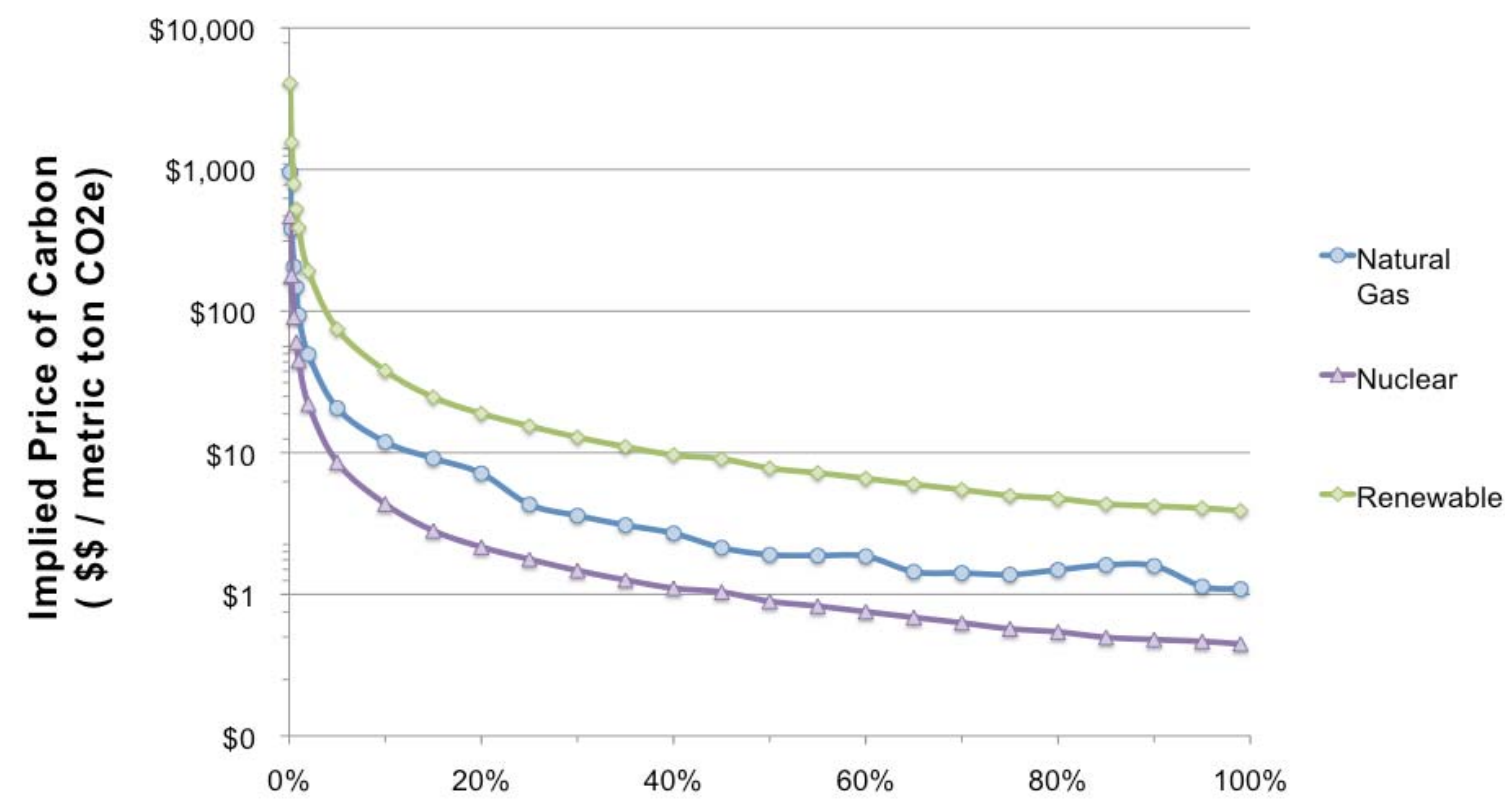

Figure 1. Impact on IPC of the proportion of energy supported by a subsidy that does not specify a specific per-unit energy payment. Example is for replacing subsidized fuels for electricity generation with U.S. grid average electricity. 
Once the subsidy is valued (step \#3), step 4 requires the analyst to make a determination on whether the full cost and impact of the subsidy are observed in a single year, or extend for multiple years. For example, a subsidy to incentivize the construction of low-carbon infrastructure will reduce emissions over the entire lifetime of that generating facility at a cost that may be incurred for only a small portion of the facility's design lifetime. Such a subsidy would typically have a lower IPC than if all costs and benefits were accrued over a single year.

Finally, a decision needs to be made on whether to use "simple" emissions or lifecycle emissions when calculating the emissions associated with a subsidized energy source and its potential replacement fuel. "Simple" emissions, which are often termed direct emissions, are those that directly produce greenhouse gas emissions when energy is used. An example is the emissions that directly result from the combustion of coal to produce electricity. Lifecycle emissions are the aggregate emissions that result from the full lifecycle of fuel extraction, transport, refining, and use. If lifecycle values are used, then the boundaries of the lifecycle analysis need to be clearly described and rigorously implemented. For subsidies that support electricity production, this study only considers simple emissions. This approach has significant drawbacks; in so much as the production of the infrastructure required for "zero-carbon" generating resources (e.g. wind, solar, nuclear) emits greenhouse gasses that can be indirectly linked to energy production from these resources. However, most proposed policies for reducing greenhouse gas emissions from these resources only consider simple point source emissions, and thus this approach is reasonable for evaluating the IPC of policies intended to reduce emissions associated with electricity generation.

Lifecycle emissions are considered for production of transportation fuels; because the method used to produce the refined fuel from its raw feedstock can significantly alter the lifecycle emissions cost and the associated IPC. For example, the U.S. biofuels industry uses a broad range of methods to produce biofuels, and this variance needs to be considered. Regulations for fuel production and use increasingly adopt the lifecycle emissions cost of such fuels, with notable examples being the California Low Carbon Fuel Standard, and the 2007 Energy Independence and Security Act that forbid the U.S. government from purchasing fuels from alternative resources that had a higher lifecycle carbon cost than fuels produced from crude oil. The carbon emissions values used in this study are discussed in Appendix II. 


\section{Case Studies of IPC from Federal Subsidies in 2007}

The methods described above have been used to survey a subset of federal energy subsidies to assess the range of IPC values of some of the largest federal tax credits and payments that impact energy markets. Case studies were selected to provide an overview of the existing federal energy subsidies. Four case studies for subsidies that support renewable energy production were performed. The data inputs for each of these calculations are provided in Appendix III. These four cases are:

1. Fuel specific subsidies in electricity generation - subsidies for electricity generation from specific fuels, calculated by assuming simple emissions.

2. New Technology Credit - federal tax credit to support renewable electricity production, analyzed using simple emissions data.

3. Ethanol and biodiesel credits - federal tax credits and deferrals to incentivize production of biofuels, analyzed using lifecycle emissions data.

4. Federal utilities and support to rural utilities - federal financial support given to federal power marketing administrations (PMA's) and rural utilities, which provided over $40 \%$ of total U.S. renewable electricity in 2007 , and analyzed using simple emissions data.

\section{Case 1-Fuel specific subsidies to electricity generation}

A significant issue in climate policy is the amount of subsidy given to specific fuels. Advocacy groups often highlight this issue in their energy and environmental policy studies. For example, a recent study by the Environmental Law Institute [2] indicates that over $\$ 72.5$ billion on federal subsidies went to fossil fuels from $2002-2008$ while only $\$ 29.0$ billion went to renewable alternatives over the same time period. This study exempted R\&D expenditures, and did not subdivide the subsidies according to the energy service sector they support. It also included the Foreign Tax Credit as a subsidy for fossil fuel production, which was not included in a comparable EIA study that evaluated total subsidies in 2007 [1]. A 2000 study by the Renewable Energy Policy Project evaluated subsidies by fuel, and included R\&D and statutory limitations on accident liability as subsidies to specific types of fuels [3]. As a third example, a report by the United Nations Environment Program estimates the value of energy subsidies in non-OECD nations in terms of the difference between actual price and modeled LCOE for the type of energy supported (e.g. oil, natural gas, coal, electricity) [4]. These studies set a precedent for assessing energy subsidies from the perspective of "total support to a given resource type". Consequently, this analysis also investigates IPC from this perspective.

The IPC of a subsidy or set of subsidies is defined in terms of the replacement fuel that would have been used in the absence of the subsidy. This is difficult to establish for economy-wide energy use, but can be evaluated within the context of a specific energy service where the energy choices are more clearly defined. This case study evaluates the IPC of fuel-specific subsidies in the electricity sector; where the replacement energy can be clearly defined as "coal-fired", "natural gas fired", "U.S. grid average", "average renewable", or "nuclear". Nuclear is chosen as a model electricity resource because its GHG emissions are effectively zero from a simple emissions perspective, and comparable to those from wind and solar electricity. For this case, 
subsidies come from Table ES4 of EIA's 2008 report [1], and include total direct and tax expenditures. R\&D expenditures and federal electricity support are not included.

\begin{tabular}{|c|c|c|c|c|c|}
\hline \multirow{2}{*}{$\begin{array}{l}\text { Replacement } \\
\text { Generation } \\
\text { could be used in } \\
\text { absence of subsidy }\end{array}$} & \multicolumn{5}{|c|}{ Fuel-Specific Subsidies to Electricity Generation } \\
\hline & Refined coal & $\begin{array}{c}\text { Non-refined } \\
\text { Coal }\end{array}$ & Natural Gas & $\begin{array}{l}\text { U.S. average } \\
\text { renewable }\end{array}$ & Nuclear \\
\hline $\begin{array}{l}\text { Replacement with coal } \\
\text { fired electricity }\end{array}$ & -- & -- & $\$ 0.40$ & $\$ 2.20$ & $\$ 0.25$ \\
\hline $\begin{array}{l}\text { Replacement with U.S. } \\
\text { grid average electricity }\end{array}$ & $(\$ 70)$ & $(\$ 0.30)$ & $\$ 1.40$ & $\$ 3.70$ & $\$ 0.40$ \\
\hline $\begin{array}{c}\text { Replacement with } \\
\text { natural gas fired } \\
\text { electricity }\end{array}$ & $(\$ 50)$ & $(\$ 0.20)$ & -- & $\$ 5.30$ & $\$ 0.60$ \\
\hline $\begin{array}{l}\text { Replacement with U.S. } \\
\text { average renewable } \\
\text { electricity }\end{array}$ & $(\$ 30)$ & $(\$ 0.10)$ & $(\$ 0.60)$ & -- & $\$ 8.40$ \\
\hline $\begin{array}{l}\text { Replacement with } \\
\text { nuclear electricity }\end{array}$ & $(\$ 30)$ & $(\$ 0.10)$ & $(\$ 0.50)$ & $(\$ 70)$ & -- \\
\hline $\begin{array}{c}\text { total electrical } \\
\text { generation associated } \\
\text { with subsidy } \\
\text { (billion } \mathrm{kWh} \text { ) }\end{array}$ & 76 & 2,016 & 897 & 353 & 806 \\
\hline $\begin{array}{l}\text { total value of subsidy to } \\
\text { electricity generation } \\
\text { (million } \$ \text { ) }\end{array}$ & $\$ 2,156$ & $\$ 264$ & $\$ 203$ & $\$ 727$ & $\$ 199$ \\
\hline
\end{tabular}

Table 1. IPC values ( $\$$ per metric ton $\mathrm{CO} 2 \mathrm{e}$ ) for replacement of electricity from the subsidized resource with an equal amount from an alternative resource, assuming that elimination of the subsidy would result in replacement of $100 \%$ of the subsidized energy. Average renewable refers to total U.S. renewable generation in 2007 (as per EIA), and is explained in Appendix II.

\section{Case Results}

Results from these calculations are provided in Table 1. Fuel-specific subsidies are apportioned to electricity based on the amount of total fuel use that goes to electricity production, and it is assumed that $100 \%$ of the electricity produced from the fuel-specific subsidies is attributable to the subsidy. Calculations assume simple emissions and subsidy values as specified by EIA [1]. Total generation is as per EIA [5]. The results from these calculations reveal a diverse range of IPC values. The estimated IPC is dependent upon the total value of the subsidy and the emissions profile of potential replacement fuels. One surprising finding is that over $60 \%$ of the fuel-specific subsidies that supported electricity production in 2007 went to the production of 
refined coal, which provides less than $2 \%$ of total electricity production. This generates a strongly negative IPC, and incentivizes increased greenhouse gas emissions.

When refined coal is excluded from the analysis of coal subsidies, the IPC is significantly less negative. There is still an incentive for increased greenhouse gas emissions, but the incentive is considerably smaller. These other coal subsidies primarily provide tax credits for investment in mine safety, tax expensing for special benefits to disabled coal miners, and capital gains adjustments for income on royalties from coal mines. EIA lists these as subsidies that support electricity production from coal [1], and we adopt their methodology for this case. It should be noted that the value of this subsidy is extremely small in comparison with the amount of supported generation, and thus it likely has minimal impact on the overall use of coal for electricity generation.

The IPC for tax credits that support electricity generation from natural gas is generally small, and varies between slightly positive and slightly negative depending upon the emissions profile of the prospective replacement fuel. Nuclear energy has only one tax credit, the modification of special rules for nuclear decommissioning that was passed as part of the Energy Policy Act of 2005. This policy has a low IPC, except when compared to replacement with renewable energy. Nuclear has a notably higher IPC when used to replace renewable generation than when used to replace coal or natural gas. This happens because renewable electricity emits few greenhouse gasses per unit energy, and there is less marginal value to be gained from replacing a low emitting resource (total of all renewable electricity resources) with a zero emitting resource (nuclear).

Subsidies for renewable electricity generation comprise approximately $20 \%$ of total tax and direct support to electricity generation in 2007. When grouped together as total subsidies that support generation from all renewable resources, their IPC is generally low; though their IPC value is notably higher than for other electrical generation sources who emit fewer greenhouse gasses than U.S. grid average electricity. The large negative IPC for replacement of total renewable electricity with nuclear electricity arises from the fact that biowaste electricity, geothermal electricity, and hydropower electricity generated from large reservoirs all emit low levels of greenhouse gasses. Combined, these resources contribute approximately $90 \%$ of total U.S. renewable electricity while wind and solar currently contribute approximately 10\%. Thus, subsidizing low-emitting renewable resources increases emissions in contrast with support to a "zero emission" resource such as nuclear, solar, or wind; and at a high marginal cost.

\section{Considerations for IPC Calculations}

Evaluating the IPC from a total subsidized resource perspective is problematic, and prone to large errors that arise from assumptions regarding subsidy attribution and impact. If subsidies to different electricity generating resources have varying impact rather than $100 \%$ each, then their resulting IPC can be considerably different than under the $100 \%$ impact assumption. For example, almost $95 \%$ of total renewable subsidies in 2007 went to wind generation, yet wind accounted for only $10 \%$ of total renewable electricity generation in the U.S. Treating all renewable electricity generation as one type of fuel attributes energy produced via all U.S. renewable generation (approx. 70\% hydropower, 11\% biomass, 10\% wind and solar, 5\% 
biowaste, $4 \%$ geothermal) with subsidies that predominantly supported wind. This attributes generation from unsubsidized resources to the renewable subsidy, and can make the renewable subsidy appear more cost effective than it may actually be. Corollary problems exist for coal, natural gas, and nuclear generation. Consequently, if subsidies do not have a statutory per-unitenergy payment, then the amount of incremental energy production attributable to the subsidy must be accurately quantified (e.g. Figure 1). Failure to do this can lead to incorrect conclusions.

\begin{tabular}{|c||c|c|c|c|c|}
\hline \multicolumn{2}{|c||}{$\begin{array}{c}\text { Replacement } \\
\text { Generation } \\
\% \text { replaced with U.S. } \\
\text { grid average electricity }\end{array}$} & \multicolumn{4}{|c|}{ Subsidized Electricity Generating Resource } \\
\hline \hline $\begin{array}{c}5 \% \text { replaced with grid } \\
\text { average }\end{array}$ & $(\$ 1,450)$ & $(\$ 6.60)$ & $\$ 27.00$ & $\$ 74.00$ & $\$ 8.40$ \\
$\begin{array}{c}10 \% \text { replaced with grid } \\
\text { average }\end{array}$ & $(\$ 730)$ & $(\$ 3.30)$ & $\$ 14.00$ & $\$ 37.00$ & $\$ 4.20$ \\
$\begin{array}{c}25 \% \text { replaced with grid } \\
\text { average }\end{array}$ & $(\$ 300)$ & $(\$ 1.30)$ & $\$ 5.50$ & $\$ 15.00$ & $\$ 1.70$ \\
$\begin{array}{c}50 \% \text { replaced with grid } \\
\text { average }\end{array}$ & $(\$ 150)$ & $(\$ 0.70)$ & $\$ 2.70$ & $\$ 7.40$ & $\$ 0.80$ \\
\hline $\begin{array}{c}100 \% \text { replaced with grid } \\
\text { average }\end{array}$ & $(\$ 70)$ & $(\$ 0.30)$ & $\$ 1.40$ & $\$ 3.70$ & $\$ 0.40$ \\
\hline
\end{tabular}

Table 2. IPC values (\$ per metric ton $\mathrm{CO} 2 \mathrm{e}$ ) for replacement of electricity from the subsidized resource with an equal amount of electricity generated from U.S. grid average electricity, accounting for variability in the amount of energy replacement that would occur in the absence of the subsidy. Average renewable refers to total U.S. renewable generation in 2007 (as per EIA), and is explained in Appendix II.

Results from Table 2 demonstrate how variable impact of the subsidy on energy generation affects IPC. For example, contrast IPC estimates for replacement of natural gas and renewable with various levels of grid-average electricity on the basis of electricity subsidies in 2007.

- If the total subsidies in 2007 impacted $100 \%$ of generation for both natural gas and renewable electricity; then the IPC for total renewable electricity is more than double that for total natural gas.

- Contrarily, if total renewable subsidies impacted more than $50 \%$ of total renewable generation while total natural gas subsidies impacted $10 \%$ or less of total natural gas generation; then the reverse is true. The IPC for total natural gas is more than double that for total renewable electricity. 
Clearly, the impact of the subsidy on generation is a critically important factor. This impact is difficult to quantify from a total resource perspective, and thus this approach is problematic. The total resource approach helps to understand how much the U.S. Treasury spends in certain types of subsidies; but is not well suited to understanding how effective those subsidies are in reaching climate goals. Consequently, IPC values calculated on a total resource basis should be treated with caution. IPC estimates are much more reliable when evaluated with respect to the structure and function of individual subsidies or groups of subsidies.

\section{Implications of Case Results for Climate Policy}

Results from this case indicate that the current set of federal energy subsidies are acting at crosspurposes with regards to climate policy. As of 2007, a large portion of federal energy payments incentivized increased emissions. These negative IPC interventions likely slowed the pace of greenhouse gas emissions reductions, while also incurring a cost to the U.S. Treasury. The subsidy with the most negative IPC was the Alternative Fuel Production Credit. The original purpose of this subsidy, as per P.L. 96-223 (1980), was to incentivize production of coal bed methane. It was modified by EPACT 1992 to include refined coal; and H.R. 1424 (Oct. 2008) extended the date for which plants could become eligible for the credit through 2010 . This credit is scheduled to expire, but its current status is still uncertain. It is worth noting that investigations of this subsidy by major news organizations have suggested that the main economic value in producing refined coal is in collecting the tax credit [6]; and that the product may produce fewer beneficial reductions in emissions of sulfur, nitrogen, and mercury $(\mathrm{Hg})$ than advertised.

Results from this case suggest that, depending on the impact of federal subsidies on provision of electricity services, subsidies to natural gas and nuclear electricity generation can potentially provide more greenhouse gas emissions reductions per dollar cost to the U.S. Treasury than subsidies to support renewable electricity production. This is a peculiar result, and could be interpreted to mean that elimination of some fossil fuel subsidies could be counterproductive to greenhouse gas reduction goals. However, such a conclusion would be hasty. The weaknesses in the total resource method of IPC calculation allow for two contrasting possibilities.

1. Renewable resource subsidies reduce electricity sector greenhouse gas emissions at a higher marginal cost than comparable subsidies to coal and nuclear. Despite advances, renewable resources are still more expensive per unit energy than nuclear and natural gas and the U.S. grid is still designed around a paradigm of base load generating capacity. Thus, renewable generation is a higher cost option for reducing GHG emissions from America's predominantly coal-fired electricity base.

2. Renewable resource subsidies reduce electricity sector greenhouse gas emissions at a cost that is competitive with coal and nuclear, but the differing impact of total fuel subsidies on actual generation may bias the result. If subsidies do not significantly stimulate natural gas and nuclear generation, but greatly stimulate renewable generation, then an IPC calculation that assumes equal impact of subsidies would be incorrect (e.g. Table 2). This would bias the IPC calculations to favor subsidies whose actual impact is over estimated.

There is evidence to support both of these possibilities. The suggestion that natural gas and nuclear may provide less expensive ways to reduce greenhouse gas emissions associated with electricity generation over the near term is supported by McKinsey \& Company's analysis of the 
cost curve for greenhouse gas abatement [7], the fact that nuclear and natural gas combine to produce approximately four times as much electricity as renewable resources do, and that electricity generators are already shifting toward nuclear and natural gas in the absence of large, focused subsidies. This evidence is not definitive, but it does suggest that mild incentives to shift electricity generation toward nuclear and natural gas resources using currently commercialized technology could potentially provide more cost effective climate mitigation than corollary incentives to produce electricity from renewable resources. The alternative, that the total resource method for estimating IPC contains internal bias that may artificially enhance the value of nuclear and natural gas subsidies, is supported by calculations summarized in Table 2 and the observation that use of renewable resources is growing rapidly around the world under a variety of policy regimes.

Aside from the observation that a U.S. subsidies to coal production in 2007 were not in alignment with U.S. climate policy goals, results from this case are inconclusive. There is evidence to suggest that strong incentives to spur renewable electricity generation may provide less cost effective options for greenhouse gas mitigation than milder subsidies that target other electricity options that produce fewer greenhouse gasses than the current U.S. mix (e.g. natural gas, nuclear). However, the weaknesses of the method for estimating an IPC for total subsidies to a given type of electricity generating resource cloud the issue. Additional, "bottom-up" analyses that can account for the proportion of electricity generation that is impacted by the subsidies are needed before firm conclusions can be reached.

\section{Case 2-Support to renewable electricity from the New Technology Credit}

Greater than $80 \%$ of federal tax credits and direct payments supporting renewable electricity generation come from the New Technology Credit [1], which is often referred to as the wind production tax credit. This credit provides a range of renewable generation technologies with a per-unit energy tax credit that is specific to a given renewable generating facility that meets statutory qualifying criteria. Because this is a direct subsidy that is granted on a per unit energy basis, the IPC can be calculated by comparing the emissions profile for the subsidized renewable resources with alternative options (e.g. coal, natural gas, grid average, nuclear, wind, solar). There are two ways to evaluate the IPC of this tax credit; annual basis and lifetime basis. For the annual basis, the credit is evaluated in terms of annual payments and emissions savings. For the lifetime basis, costs and benefits accrue over multi-year time periods. For this case, calculations assume simple emissions and per-unit energy subsidy values as specified by EIA [1].

\section{Case Results}

Results from IPC calculations assuming an annual basis for the credit are provided in Table 3. This approach attributes all the subsidized electricity generated in a single year to the corollary tax credits given by the U.S. Treasury to energy producers within that year; and estimates the resultant emissions savings for that year. All costs and benefits for the tax credit are accrued annually, and longer-term costs and benefits are not considered. Results from this calculation are presented in Table 3 and demonstrate that, depending upon which alternative resource replaces a given renewable resource; the IPC for the New Technology Credit can range from $-\$ 1,940$ per 
metric ton $\mathrm{CO} 2 \mathrm{e}$ (geothermal versus nuclear) to $\$ 970$ per metric ton $\mathrm{CO} 2 \mathrm{e}$ (geothermal versus average U.S. renewable electricity). If U.S. grid average electricity replaces renewable electricity in the absence of a subsidy, then IPC ranges from \$16 to \$44 per metric ton; depending upon which renewable resource is subsidized.

\begin{tabular}{|c|c|c|c|c|c|c|}
\hline \multirow{2}{*}{$\begin{array}{l}\text { Replacement } \\
\text { Generation } \\
\text { could be used in } \\
\text { absence of subsidy }\end{array}$} & \multicolumn{6}{|c|}{$\begin{array}{c}\text { Subsidized Electricity Generation from the New Technology Credit, } \\
\text { Annual Basis }\end{array}$} \\
\hline & $\begin{array}{l}\text { Open-loop } \\
\text { biomass }\end{array}$ & Geothermal & Hydroelectric & $\begin{array}{l}\text { Landfill gas } \\
\text { and MSW }\end{array}$ & Solar & Wind \\
\hline $\begin{array}{l}\text { Replacement with coal } \\
\text { fired electricity }\end{array}$ & $\$ 10$ & $\$ 19$ & $\$ 10$ & $\$ 16$ & $\$ 19$ & $\$ 19$ \\
\hline $\begin{array}{l}\text { Replacement with U.S. } \\
\text { grid average electricity }\end{array}$ & $\$ 16$ & $\$ 32$ & $\$ 17$ & $\$ 44$ & $\$ 32$ & $\$ 32$ \\
\hline $\begin{array}{l}\text { Replacement with natural } \\
\text { gas fired electricity }\end{array}$ & $\$ 23$ & $\$ 45$ & $\$ 23$ & $\$ 200$ & $\$ 45$ & $\$ 45$ \\
\hline $\begin{array}{c}\text { Replacement with U.S. } \\
\text { average renewable } \\
\text { electricity }\end{array}$ & $\$ 320$ & $\$ 970$ & $\$ 660$ & $(\$ 28)$ & $\$ 640$ & $\$ 640$ \\
\hline $\begin{array}{l}\text { Replacement with } \\
\text { nuclear electricity }\end{array}$ & -- & $(\$ 1,940)$ & $(\$ 630)$ & $(\$ 26)$ & -- & -- \\
\hline $\begin{array}{c}\text { total generation } \\
\text { associated with subsidy } \\
\text { (billion } \mathrm{kWh} \text { ) }\end{array}$ & 0.35 & 0.35 & 0.09 & 0.80 & 0.03 & 27.7 \\
\hline $\begin{array}{l}\text { Treasury estimated credit } \\
\text { allowed, } 2007 \text { (million } \\
\$ \$ \text { ) }\end{array}$ & $\$ 4.2$ & $\$ 8.3$ & $\$ 1.0$ & $\$ 9.6$ & $\$ 0.75$ & $\$ 666$ \\
\hline $\begin{array}{l}\text { EIA estimated credit } \\
\text { based on generation, } \\
2007 \text { (million } \$ \$ \text { ) }\end{array}$ & $\$ 3.3$ & $\$ 6.6$ & $\$ 0.8$ & $\$ 6.8$ & $\$ 0.59$ & $\$ 526$ \\
\hline $\begin{array}{l}\text { Payment per unit energy } \\
\quad(\$ \text { per } M W h)\end{array}$ & $\$ 9.50$ & $\$ 19.00$ & $\$ 9.50$ & $\$ 9.50$ & $\$ 19.00$ & $\$ 19.00$ \\
\hline
\end{tabular}

Table 3. IPC values (\$ per metric ton CO2e) for the New Technology Credit, when calculated on an annual basis. Values derived from replacement of electricity from the subsidized resource with an equal amount of electricity generated from an alternative resource. Ancillary information on estimated credit allowed, total associated generation, and estimated credit paid are also given.

The IPC of the New Technology Credit can also be estimated on a lifetime basis; which accounts for the fact that this credit provides annual payments for a term of 5-10 years, depending upon the technology choice and the year in which the facility qualified [1]. Most of the costs of renewable electricity generation are associated with the purchase and installation of new infrastructure. Subsequent operating costs are very low. Thus, this credit can be considered to subsidize the cost of building renewable infrastructure, thereby reducing the lifetime costs of producing electricity for a qualifying renewable electricity generation facility. If costs are calculated over the lifetime of the credit (currently 10 years for all technologies), and benefits accrue for the entire period for which the renewable electricity infrastructure operates, then the 
benefits are much higher and the IPC correspondingly lower. This effect is investigated in Table 4, which repeats the calculations made in Table 3 while accounting for multi-year tax credits and emissions savings. As before, calculations assume simple emissions and subsidy values as specified by EIA [1]. Using this methodology, the IPC for the New Technology Credit can range from $-\$ 570$ per metric ton CO2e (geothermal versus nuclear) to $\$ 290$ per metric ton CO2e (geothermal versus average U.S. renewable electricity). If U.S. grid average electricity replaces renewable electricity in the absence of a subsidy, then IPC ranges from $\$ 5$ to $\$ 19$ per metric ton; depending on which resource is subsidized.

\begin{tabular}{|c|c|c|c|c|c|}
\hline \multirow{2}{*}{$\begin{array}{l}\text { Replacement } \\
\text { Generation } \\
\text { could be used in } \\
\text { absence of subsidy }\end{array}$} & \multicolumn{5}{|c|}{$\begin{array}{l}\text { Subsidized Electricity Generation from the New Technology } \\
\text { Credit, Lifetime Basis }\end{array}$} \\
\hline & $\begin{array}{l}\text { Open-loop } \\
\text { biomass }\end{array}$ & Geothermal & Hydroelectric & $\begin{array}{l}\text { Landfill gas } \\
\text { and MSW }\end{array}$ & $\begin{array}{l}\text { Wind and } \\
\text { Solar }\end{array}$ \\
\hline $\begin{array}{l}\text { Replacement with coal } \\
\text { fired electricity }\end{array}$ & $\$ 3$ & $\$ 6$ & $\$ 3$ & $\$ 5$ & $\$ 11$ \\
\hline $\begin{array}{l}\text { Replacement with U.S. } \\
\text { grid average electricity }\end{array}$ & $\$ 5$ & $\$ 10$ & $\$ 5$ & $\$ 13$ & $\$ 19$ \\
\hline $\begin{array}{l}\text { Replacement with natural } \\
\text { gas fired electricity }\end{array}$ & $\$ 7$ & $\$ 14$ & $\$ 7$ & $\$ 58$ & $\$ 27$ \\
\hline $\begin{array}{l}\text { Replacement with U.S. } \\
\text { average renewable } \\
\text { electricity }\end{array}$ & $\$ 95$ & $\$ 290$ & $\$ 200$ & $(\$ 8)$ & $\$ 380$ \\
\hline $\begin{array}{l}\text { Replacement with } \\
\text { nuclear electricity }\end{array}$ & -- & $(\$ 570)$ & $(\$ 190)$ & $(\$ 8)$ & -- \\
\hline Term of subsidy (years) & 10 & 10 & 10 & 10 & 10 \\
\hline $\begin{array}{l}\text { Approximate lifetime of } \\
\text { facility (years) }\end{array}$ & 40 & 40 & 40 & 40 & 20 \\
\hline
\end{tabular}

Table 4. IPC values (\$ per metric ton CO2e) for the New Technology Credit, when calculated on a lifetime basis. Values derived from replacement of electricity from the subsidized resource with an equal amount of electricity generated from an alternative resource.

\section{Considerations for IPC Calculations}

These calculations indicate that IPC values for the New Technology Credit can vary widely. This variance occurs because the IPC depends on (i) whether the credit is valued on an annual or lifetime basis, (ii) which renewable electricity resource is being subsidized, and (iii) which alternative fuel would replace that electricity in the absence of the subsidy. These three factors create four methodological considerations that should be taken into account when conducting IPC calculations and evaluating results. 
- Different per-unit energy payments yield different IPC values.

- Different time periods for accruing costs and emissions benefits yield different IPC values.

- If per unit energy payments and time periods are equal, then subsidies that support switches that result in larger reductions in greenhouse gas emissions per unit energy have a lower IPC.

- IPC values become very large (positive or negative) when the incremental change in greenhouse gas emissions per unit energy is small.

In general, lower subsidy payments and greater emissions reductions per unit energy for the subsidized fuel lead to lower IPC values. The most beneficial IPC values occur when a small payment stimulates the replacement of a high-carbon resource (e.g. coal, U.S. grid average) with a low carbon replacement. This is an intuitive result. Yet, the large range of IPC values that can occur within a single subsidy that supports deployment of low carbon electricity generation is surprising and needs to be accounted for.

These results are generally consistent with results from case \#1, when the differences in the total amount of subsidized electrical generation are taken into account. In 2007, the New Technology Credit provided approximately $\$ 690$ million worth of subsidy to support 29 billion $\mathrm{kWh}$ of renewable electricity generation. In case \#1, \$727 million worth of total subsidy was assumed to support approximately 353 billion $\mathrm{kWh}$ of annual renewable electricity production in the same year. Thus, the New Technology Credit supported slightly less than $10 \%$ of total renewable electricity generation in 2007. If the annual basis calculations for this case are (i) compared to total annual subsidies for renewable electricity production from case \#1, and (ii) evaluated in terms of replacement with U.S. grid average electricity; then IPC estimates from Table 3 (row 2) are equivalent to results from case $\# 1$ where $10 \%$ to $25 \%$ of total renewable electricity generation is impacted by total renewable subsidies (Table 2, column 4).

\section{Implications of Case Results for Climate Policy}

The New Technology Credit provides an annual payment over a multi-year period, and has both an annual cost that must be accrued in the U.S. budget and a longer-term cost and value. Given this duality, this subsidy can be reasonably evaluated on either a one-year return basis (annual) or long-term reduction basis (lifetime). IPC values for the New Technology Credit are two to three times lower when evaluated on a lifetime basis as opposed to an annual basis. This is reasonable, as infrastructure investments have term-limited costs that yield benefits for multiple years while annual payments yield a benefit for only the year that the benefit is given. Thus, results from comparison of these two analytical perspectives suggest that incentivizing installation of low carbon infrastructure (e.g. generating facilities, transmission) is likely to be a more cost effective strategy for reducing greenhouse gas emissions than subsidizing annual reductions. It should also be noted that neither the annual basis method nor the project-lifetime basis method is more "correct" than the other. These two methods simply apply to different questions. The annual basis method is more suitable for evaluating costs and possible impacts over the short-term. The project lifetime basis method is more suited to long-term planning. Different approaches must be taken when considering the best options for near-term progress as opposed to long-term goals. 
The type of infrastructure supported is also important to consider. Longer-lasting infrastructure yields more long-term emissions reductions per dollar investment than shorter-lasting infrastructure. For example, the lifetime-basis IPC for wind and solar is higher because wind and solar installations typically have a design lifetime of 20 years, as opposed to the $40+$ year design lifetime for large, centralized power facilities needed for biomass, biowaste, geothermal, and hydropower. Also, infrastructure investments can be structured in ways that reduce private sector investment risk rather than provide a direct subsidy from the U.S. Treasury. A loan guarantee that never pays a single dollar can result in a decision to build higher-risk, capital intensive, lower-carbon generating infrastructure as opposed to lower-risk, lower capital, highercarbon infrastructure. Such an approach could yield better returns on climate mitigation investment than production tax credits, and should be evaluated further.

In closing, the observation that different time-spans for evaluation can yield different IPC values highlights a climate policy conundrum. If the IPC is different depending upon the time frame of the analysis, then some incentives that may be more cost effective over the longer term may be less cost effective over the shorter term. In this case, incentivizing longer-term goals may slow progress towards nearer-term objectives. The reverse could also be true. When this policy risk is considered in addition to the large variance in IPC across different replacement scenarios (regardless of time frame), it becomes apparent that subsidizing utilization of specific resources may not provide the most optimum greenhouse gas mitigation strategy. Improved synergy and greater cost effectiveness could be potentially be achieved by targeting subsidies toward the magnitude of the emissions savings rather than the use of a particular type of resource. This is an underlying principle of cap and trade strategies, and could potentially be adopted to improve the ability of energy subsidies to incentivize greenhouse gas emissions reductions.

\section{Case 3-Ethanol and biodiesel}

An important objective of current climate policy, while also meeting other energy policy objectives, is to reduce the greenhouse gas emissions from transportation fuels through the use of domestic biofuels. This objective is supported by one of the largest federal tax subsidies in 2007, the Volumetric Ethanol Excise Tax (VEETC), which provides a payment of $\$ 0.51$ per gallon of pure ethanol blended into fuel. Similarly, the Biodiesel and Small Agri-Biodiesel Producer Tax Credit provides a $\$ 1.00$ per gallon payment for sale of agri-biodiesel fuel from "virgin" feedstock such as soybeans or cottonseed and a $\$ 0.50$ per gallon credit to biodiesel from recycled grease. These subsidies are granted on a per-unit energy basis, and the IPC can be calculated by comparing the emissions profile of ethanol and biodiesel to that of alternative options; gasoline and low-sulfur diesel. Because these subsidies support the production of transportation fuels and have lifecycle emissions that can vary widely depending upon the heating fuel used to refine feedstock into a liquid fuel, the IPC calculation is based on lifecycle emissions instead of the simple emissions basis that used to estimate the IPC of subsidies to electricity production.

Lifecycle emissions values are strongly dependent on how the boundaries of the system are defined. For this analysis, we have adopted the well-to-wheels approach used by the GREET model developed by Argonne National Laboratory [8]. Specific lifecycle values from the GREET model used for this case study are as reported in a UC-Davis analysis of the California 
low carbon fuel standard [9], with biodiesel lifecycle estimates augmented by results from comparable studies published in the Proceedings of the National Academy of Science [10]. California grade gasoline is assumed to be the replacement fuel for ethanol and ultra-low sulfur diesel is the replacement fuel for biodiesel. IPC calculations assume a single lifecycle emissions value for the replacement fuel, while considering a range of possible lifecycle emissions values for ethanol and biodiesel. This set of assumptions oversimplifies the issue somewhat, as the IPC value would be different if other fossil fuel formulations were used as replacement fuels instead of California grade gasoline and ultra-low sulfur diesel. However, the purpose of this case study is to evaluate how the IPC calculation can be used to broadly estimate the climate value of transportation fuel subsidies; and thus this simplification is merited for the purpose of this study.

\section{Case Results}

The subsidies associated with this case are assessed in terms of annual payments and associated changes in greenhouse gas emissions. Calculations assume lifecycle emissions as described in Appendix II, and subsidy values as specified by EIA [1]. Results are presented in Table 5.

\begin{tabular}{|c|c|c|c|c|c|}
\hline \multirow{2}{*}{$\begin{array}{l}\text { Replacement Fuels } \\
\text { could be in used in } \\
\text { absence of subsidy }\end{array}$} & \multicolumn{5}{|c|}{ Subsidized Biofuel } \\
\hline & $\begin{array}{c}\text { corn based, } \\
\text { coal heated } \\
\text { ethanol }\end{array}$ & $\begin{array}{c}\text { corn based, } \\
\text { gas heated } \\
\text { ethanol }\end{array}$ & $\begin{array}{c}\text { corn based, } \\
\text { biomass } \\
\text { heated ethanol }\end{array}$ & $\begin{array}{c}\text { cellulosic } \\
\text { ethanol } \\
\text { (estimate) }\end{array}$ & Biodiesel \\
\hline $\begin{array}{l}\text { Replacement with } \\
\text { California grade gasoline }\end{array}$ & $(\$ 220)$ & $\$ 430$ & $\$ 170$ & $\$ 82$ & $\begin{array}{c}\text { not } \\
\text { applicable }\end{array}$ \\
\hline $\begin{array}{l}\text { Replacement with ultra- } \\
\text { low sulfur diesel }\end{array}$ & $\begin{array}{c}\text { not } \\
\text { applicable }\end{array}$ & $\begin{array}{c}\text { not } \\
\text { applicable }\end{array}$ & $\begin{array}{c}\text { not } \\
\text { applicable }\end{array}$ & $\begin{array}{c}\text { not } \\
\text { applicable }\end{array}$ & $\$ 120-\$ 170$ \\
\hline
\end{tabular}

Table 5. IPC values ( $\$$ per metric ton $\mathrm{CO} 2 \mathrm{e}$ ) for corn ethanol, cellulosic ethanol and biodiesel, derived from replacement of fuel with California grade gasoline or ultra-low sulfur diesel.

The IPC of corn ethanol is dependent upon the heat source used to convert corn feedstock into ethanol. If coal heating is used, then the IPC is negative, indicating that the subsidy supports increased emissions. If natural gas or biomass is used for process heat, then the IPC is positive and ethanol reduces greenhouse gas emissions relative to California grade gasoline. Cellulosic ethanol has the lowest IPC, reflecting the greater efficiency of utilizing advanced bioprocessing to convert cellulosic feedstock into fuel. The range of biodiesel values reflects two different estimates of the lifecycle emissions of biodiesel within the same system boundaries. This range is higher than for cellulosic ethanol, but lower than any of the values for corn ethanol. 


\section{Considerations for IPC Calculations}

The IPC values for ethanol and biodiesel are significantly greater than those previously estimated for production of electricity, apparently suggesting that much greater value could be made by focusing climate efforts on replacement of high carbon electricity sources with low carbon electricity sources. However, the IPC values for electricity are based on simple emissions, while the values for ethanol and biodiesel are based on lifecycle values. These two sets of numbers can only be compared in a limited fashion, with care taken to ensure that results are not overinterpreted. The best comparison would be between lifecycle emissions for provision of electricity services and lifecycle emissions from transportation fuel services; so long as the calculations use the same boundary conditions. For example, comparing transportation fuels with electricity generation on an energy services basis would likely require that factors such as reliability be taken into account. If so, then electricity calculations would need to account for the capacity factor of generation needed to ensure reliable generation. Provision of reliable electricity services from wind and solar generation requires backup capacity from other sources (e.g. natural gas, hydropower); and thus emissions from load-leveling activities would need to be accounted for in a service-based lifecycle calculation.

\section{Implications of Case Results for Climate Policy}

Even though IPC values derived from simple emissions calculations are not easily comparable to those derived from lifecycle emissions, the observation that lifecycle emissions based biofuels IPC values are approximately 5 - 25 times higher than simple emissions based renewable electricity IPC values has important policy implications. At a high level, this comparison suggests that the IPC for low carbon electricity production is likely to be lower than that for biofuels. If so, then biofuels subsidies may be less effective at accelerating greenhouse gas emissions reductions than corollary investments in low carbon electricity development and deployment. A recent study evaluating the potential to extend the EU-ETS trading system to the transportation sector provides additional information that supports this possibility. This study indicated that emissions reductions from biomass-ethanol and biodiesel range from $€ 240-€ 665$ per metric ton $\mathrm{CO}_{2} \mathrm{e}$ as compared to $€ 3-€ 7$ for onshore wind and $€ 53-€ 64$ for geothermal electricity [11]. Comparison of these values suggests that low carbon electricity investments may yield 4-200 times more emissions reductions than comparable investments in biofuels. While preliminary, the combination of IPC calculations and these estimates from the EU suggest that subsidies to promote low carbon electricity may provide more cost effective emissions reductions than subsidies to promote biofuels production.

With regards to biofuels policy, the data clearly indicate that simply subsidizing ethanol production can yield undesired results. Subsidies for ethanol produced at coal-fired biorefineries increase greenhouse gas emissions relative to California grade gasoline. Other options reduce lifecycle emissions; but at a prohibitively high cost. Currently, neither ethanol nor biodiesel subsidies contain a specific requirement to reduce the lifecycle carbon emissions of biofuels beneath that of fossil fuels. Thus, if the economics of operating a facility at a given location indicate that coal provides higher profits, then this subsidy will increase lifecycle emissions for every gallon of ethanol produced at a coal-fired plant. Other process heating fuels will reduce emissions, but will likely achieve fewer emissions reductions per dollar cost to the U.S. Treasury than alternative options for reducing emissions associated with electricity generation. The 
climate value of biofuels subsidies could potentially be enhanced if the subsidy were linked to an emissions performance standard. Federal subsidies do not currently contain this link, and thus the potential benefits of doing this are unknown. However, simply using biomass as a feedstock does not guarantee emissions reductions; and additional analysis of the value of a performance standard in biofuels subsidies is certainly merited.

\section{Case 4-Federal utilities and electricity support to rural utilities}

In 2007, rural utilities and federal power marketing administrations combined to provide over $40 \%$ of total U.S. renewable electricity. This generation was predominantly hydropower, but also included a diverse range of other renewable resources; including wind, solar, geothermal, biomass co-firing, landfill gas, and gas digesters (e.g. animal waste). This generation was supported by a unique set of subsidies that the federal government provides to produce electricity for rural consumers and to commercialize the production of hydropower from federal water projects. According to EIA [1], the federal government provided approximately $\$ 767$ million of support in the form of reduced interest rates to rural utilities, the Tennessee Valley Authority (TVA), and the four power marketing administrations (BPA, WAPA, SEPA, SWPA) in 2007. This support was roughly equivalent to total tax expenditures and direct payments to renewable electricity, and has greatly contributed to the deployment of low carbon electricity generation. This support has historically been an important component of U.S. energy policy, and has a solid record of accelerating technology deployment to achieve U.S. energy policy goals. This case study contrasts the IPC for federal utility support with that of other low carbon generation subsidies to determine if there is a potential for significant IPC savings.

The federal support given to PMA's and rural utilities can be linked to electricity production through the power generation portfolio of the respective utilities. Information on the power generation portfolio is available from documents provided by the different PMA's [12-16], and EIA has provided information on the generation capabilities of rural electric cooperatives [1]. The IPC for this support can be calculated by determining the range of emissions that would have occurred if this support had not been used to build the coal, gas, nuclear, and renewable infrastructure installed by the PMA's and rural utilities; and the generation these facilities provide were replaced by an alternative resource. Calculations assume simple emissions and subsidy values as specified by EIA [1]. Values are derived by assuming that $100 \%$ of the subsidized resource would have been replaced by an alternative resource in the absence of the subsidy. This is reasonable, as absence of this subsidy would likely have prevented the construction of the original generating equipment and transmission capacity.

\section{Case Results}

Results from these calculations are presented in Table 6, and are generally consistent with results from prior cases. Subsidies that support coal electricity have a slightly negative IPC. Subsidies that support natural gas electricity have a low IPC with regards to coal and U.S. grid average electricity, but a slightly negative IPC with regards to nuclear and renewable electricity.

Subsidies that support renewable electricity and nuclear generation have a low IPC with regards to coal, natural gas, and U.S. grid average electricity; but the IPC is much higher when compared 
to competing low-carbon resources where there is a small incremental change in emissions per unit energy generated. One unique finding from this case is that renewable hydropower generation appears to have a lower IPC than for nuclear (reverse from case \#1). This may arise from the fact that the PMA's are marketing hydroelectric power from dams that have already been built for other purposes, and thus the PMA's only need to modify existing dams to produce electricity and build transmission infrastructure in order to provide electricity to their customers. Support to nuclear facilities has to justify all expenditures on the basis of power generation.

\begin{tabular}{|c|c|c|c|c|}
\hline \multirow{2}{*}{$\begin{array}{l}\text { Replacement } \\
\text { Generation } \\
\text { could be used in } \\
\text { absence of subsidy }\end{array}$} & \multicolumn{4}{|c|}{ Subsidized Electricity Generating Resource } \\
\hline & $\begin{array}{c}\text { Coal } \\
\text { Electricity }\end{array}$ & $\begin{array}{l}\text { Natural Gas } \\
\text { Electricity }\end{array}$ & $\begin{array}{l}\text { Renewable } \\
\text { Electricity }\end{array}$ & $\begin{array}{l}\text { Nuclear } \\
\text { Electricity }\end{array}$ \\
\hline $\begin{array}{l}\text { Replacement with coal } \\
\text { fired electricity }\end{array}$ & -- & $\$ 0.30$ & $\$ 1.20$ & $\$ 2.00$ \\
\hline $\begin{array}{l}\text { Replacement with U.S. } \\
\text { grid average electricity }\end{array}$ & $(\$ 0.60)$ & $\$ 1.00$ & $\$ 2.00$ & $\$ 3.30$ \\
\hline $\begin{array}{l}\text { Replacement with natural } \\
\text { gas fired electricity }\end{array}$ & $(\$ 0.40)$ & -- & $\$ 2.90$ & $\$ 4.60$ \\
\hline $\begin{array}{l}\text { Replacement with } \\
\text { renewable electricity }\end{array}$ & $(\$ 0.20)$ & $(\$ 0.40)$ & $\$ 80$ & $\$ 60$ \\
\hline $\begin{array}{l}\text { Replacement with zero- } \\
\text { emission electricity }\end{array}$ & $(\$ 0.20)$ & $(\$ 0.40)$ & $(\$ 80)$ & -- \\
\hline $\begin{array}{l}\text { total generation } \\
\text { associated with subsidy } \\
\text { (billion } \mathrm{kWh} \text { ) }\end{array}$ & 300 & 119 & 149 & 76 \\
\hline $\begin{array}{l}\text { total value of subsidy to } \\
\text { electricity generation } \\
\text { (million \$\$) }\end{array}$ & $\$ 68$ & $\$ 20$ & $\$ 173$ & $\$ 146$ \\
\hline
\end{tabular}

Table 6. IPC values ( $\$$ per metric ton $\mathrm{CO} 2 \mathrm{e}$ ) for federal support to power marketing administrations (PMA's) and rural utilities. Renewable electricity is predominantly, but not solely hydroelectric.

\section{Considerations for IPC Calculations}

There are several considerations that need to be taken into account when interpreting these results. First, federal support to PMA's and rural utilities operates under a fundamentally different subsidy mechanism than energy production tax credits. Instead of providing direct support to energy producers, federal subsidies in this area reduce borrowing costs for PMA's and rural utilities; thereby helping these entities obtain the capital that they need to build infrastructure and operate. These entities have helped to provide electricity to rural areas that the private sector did not support, and to market surplus output from hydroelectric facilities from dams whose primary purpose was flood control, navigation, and irrigation. Federal PMA's are strictly not-for-profit organizations that do not sell electricity directly to the public, but rather 
make wholesale sales to municipals, cooperatives, and some large industrial customers. This arrangement may impact IPC calculations when comparing electricity generated by federal utilities to that generated at private utilities. Rural utilities do not have the same statutory limitations as federal utilities, but do need federal assistance in order to gain the capital needed to build facilities and infrastructure to provide electricity to rural areas.

Second, the PMA calculation is subject to many of the same problems as the IPC calculations for total fuel subsidies (case \#1). Because there is not a payment per unit energy produced, it is difficult to establish how much electricity generation is attributable to the subsidy. There is a strong qualitative argument that much of this generation would not have occurred in the absence of the subsidy, but proving this assertion is difficult - and thus the assumption that $100 \%$ of the generation is associated with the subsidy is unverified. Furthermore, this calculation assumes that each year's generation is attributable to the subsidy given in that year. This is not technically true, as the subsidy reduces lending costs and actually impacts future generation. The electricity generation that occurred in 2007 is, in truth, attributable to subsidies that occurred previously. Thus, while this calculation is useful for a first-order estimate, it is technically incorrect and more comprehensive methods need to be developed. A more accurate estimation of IPC would consider the total support given to these entities since the inception of the program in relation to the total generation over the same time period. However, this data is not easily available. In the absence of this information, a rough estimate of the IPC of these subsidies is made on the basis of total payments in 2007 and total generation the same year. This methodology likely provides a maximum estimate of IPC, as it does not account for the differing time periods of federal interest support and the lifetime emissions of the low-carbon generating infrastructure.

Given these nuances, it is difficult to compare the IPC from this case with case \#1 (total fuel specific subsidies) and case \#2 (New Technology Credit). At face value, the PMA and rural utility subsidies appear to provide an IPC that is substantially lower than other incentives investigated in this study. Notably, the renewable IPC is lower than for case \#1 or case \#2. The IPC for the renewable electricity subsidy in this case is approximately $\$ 2.00$ per metric ton CO2e in comparison with replacement with grid average electricity; assuming $100 \%$ of total electricity production from PMA's and rural utilities is attributable to the subsidy. Under the same scenario in case \#1 the IPC is $\$ 3.70$ per metric ton CO2e, if it is assumed that $100 \%$ of U.S. renewable electricity would be replaced with grid average electricity in the absence of the subsidies investigated in case \#1. If the fact that the total subsidies in case \#1 actually support less than $10 \%$ of total U.S. renewable electricity generation, then the IPC in comparison with grid average electricity rises to over $\$ 37$ per metric ton $\mathrm{CO} 2 \mathrm{e}$ (Table 2 column 4 ). When renewable electricity from PMA's and rural utilities is compared with the New Technology Credit (case $\# 2$ ), the IPC for replacement of renewable generation with grid average electricity ranges from $\$ 16$ - \$44 per metric ton CO2e on a annual basis (Table 3); or $\$ 5-\$ 19$ per metric ton CO2e on a lifetime basis (Table 4). Overall, the IPC values for renewable energy in comparison with grid average electricity under scenarios in case \#1 and case \#2 are 2 - 22 times higher than for the estimate derived from the PMA and rural utility subsidies. 


\section{Implications of Case Results for Climate Policy}

This comparison indicates that federal support to PMA's and rural utilities has an IPC that is approximately $2-20$ times lower than any comparison that can be made with the IPC of the New Technology Credit or other federal support to renewable energy generation. This reduced IPC suggests that this mechanism for generating low-carbon renewable electricity may be more cost effective than other federal subsidies that provide tax credits or direct payments to energy developers. Furthermore, this policy mechanism has a long history of successful implementation of federal policy goals. Rural areas have access to affordable electricity, and most U.S. hydropower generation comes from federal utilities and PMA's. These subsidies support entities that provided over $40 \%$ of total U.S. renewable generating capacity in 2007 , and approximately $10 \%$ of U.S. nuclear capacity. They have generated a significantly higher potion of total U.S. renewable electricity production over their lifetime, which stretches back to the Rural Electrification Act of 1936. Given this history, as well as the existence of current governmental and quasi-governmental entities that have a proven record of developing low-carbon and renewable resources (e.g. PMA's, USDA rural utilities service), this type of federal support can effectively reduce the costs of building low-carbon infrastructure. It may provide a model for accelerating the introduction of low carbon electrical generation at a low cost to the federal treasury. This type of intervention might also provide net economic benefit to U.S. citizens by helping to direct financial investment to domestic infrastructure projects in parts of the country with strong low-carbon energy generating potential.

One mechanism that could achieve this could be to expand federal interest support, while specifically linking such support to accelerated the deployment of low-carbon electrical generation. Such a strategy would funnel support to existing programs, accelerate construction of low-carbon electrical infrastructure, and potentially enhance the climate mitigation value achieved through federal subsidies. Since much of the barrier to low carbon generation is in the lower economic returns relative to higher capital costs (when compared to fossil generation), this approach could directly address that barrier at a net cost to the U.S. Treasury that is likely to be substantially lower than other subsidy options.

While intriguing, more analysis of this possibility is needed. The calculations conducted in this study are preliminary, and founded upon assumptions that may not be correct. Furthermore, there is the issue of licensing and public acceptance. Even if federal incentives can reduce borrowing costs, they do not remove the licensing risk for nuclear and coal with carbon capture (with $\mathrm{CO} 2$ storage or utilization); nor do they make large wind generation facilities more acceptable to adjacent communities. Incentivizing investments in low carbon generating infrastructure through financial interventions that use the power of the government's interest support or financial guarantees rather than the government's payments can provide a new tool to accelerate deployment of electrical generation that will have a carbon footprint significantly lower than today's system. These interventions are more complex and harder to attribute than simple direct payments, but could provide a higher return on climate mitigation efforts. Further investigations are warranted, perhaps linked to small test cases conducted in partnership with rural utilities and federal PMA's. 


\section{Conclusions}

This project has developed and demonstrated a method that the Climate Change Technology Program can use to generate first order estimates of the implied price of carbon (IPC) for federal subsidies, and subsequently evaluate their effectiveness in terms of the IPC. The method is straightforward to implement, and provides sufficient detail to allow for first order analyses. IPC is a nuanced concept that cannot be calculated in a "one size fits all" manner. Implementation of the method depends both on the structure of the subsidy and the purpose of the calculation. Thus, IPC is not a single value that can be easily calculated, but is rather an analytical perspective that can be instructive or misleading depending upon how it is employed.

Four case studies were conducted to evaluate how the IPC for various renewable energy subsidies compare with other options for reducing greenhouse gas emissions. These case studies provide insight into how effective the current set of subsidies are with respect to climate goals, and how they could potentially be improved to accelerate deployment of low carbon generating technologies. General conclusions that can be drawn include,

- The current set of federal energy subsidies are acting at cross-purposes with regards to climate policy. As of 2007, a large portion of federal energy payments were either incentivizing increased emissions or providing subsidies that had a relatively high IPC. These lower value interventions likely slowed the pace of greenhouse gas emissions reductions, while also incurring a cost to the U.S. Treasury.

- Specifically incentivizing renewable energy production may not be the most cost effective way to reduce greenhouse gas emissions from the electricity sector. Comparison of results from case \#1, case \#2, and case \#4 suggest that incentives to support nuclear and natural gas could potentially provide greater $\mathrm{CO}_{2}$ e reductions per dollar coast to the federal treasury than tax subsidies specifically targeted to renewable generation.

- When subsidizing low-carbon generation, federal interest rate support to reduce the cost of borrowing may provide more cost effective greenhouse gas reductions than payments and tax credits to support comparable energy production. Comparison of case \#2 and case \#4 suggests that historic federal interest support to PMA's and rural utilities has spurred the deployment of over $40 \%$ of current U.S. renewable generating capacity at an IPC that may be up to 20 times lower than comparable tax credits and direct payments.

- Subsidies to incentivize deployment of low-carbon transportation fuels in a manner that is focused on GHG reduction may be more effective than subsidies to accelerate deployment of current generation biofuels technology. IPC analysis indicates that corn ethanol subsidies can increase lifecycle greenhouse gas emissions if coal is used to refine corn to ethanol. Greater emissions reductions lead to lower IPC, and thus focusing biofuels support on GHG reductions rather than biofuels production may be more cost effective.

- Investments in low-carbon electricity generating infrastructure may provide a highly effective way to accelerate greenhouse gas emissions reductions. Every IPC analysis conducted indicated that subsidies that promote the deployment of low-carbon infrastructure have a lower IPC than subsidies that promote specific types of energy production on an annual basis. 
With regards to methodology, IPC is a comparative value, not an absolute value. Thus, IPC calculations need to be focused on a specific question or set of questions where a comparison is illuminating. If proper care is taken, IPC information can provide guidance into how a particular type of policy can be more optimally structured. Different cases can be compared from different perspectives to evaluate policy strategies.

With regards to climate policy, three conclusions need to be highlighted. First and most importantly, current U.S. energy subsidies are not well aligned with greenhouse gas mitigation objectives. Of the three largest energy subsidies in 2007; one effectively incentivized increased emissions (refined coal, Alternative Fuel Production Credit), one appears to have marginal value (VEETC); and one appears to have solid value (New Technology Credit). These subsidies are not designed to accelerate greenhouse gas emissions at the lowest possible marginal cost; but rather to promote use of a specific type of fuel. Some have inherent climate benefits, but the subsidies are not specifically structured to maximize the climate benefit.

Second, subsidies that incentivize investments in low-carbon electrical generating infrastructure appear to have the lowest IPC and should provide the greatest climate value per dollar cost to the U.S. Treasury. Results from case \#2 and case \#4 indicate that, regardless of the way a subsidy is implemented; its value is greatest when it results in low carbon infrastructure that produces emissions savings that extend well beyond the subsidy period. Third, and perhaps most interestingly, the U.S. already has a set of policies and institutions that are well positioned to accelerate deployment of low carbon generating infrastructure at a relatively low cost to the U.S. Treasury. Federal utilities and rural utilities programs have provided subsidies that currently support over $40 \%$ of current U.S. renewable generating capacity and approximately $10 \%$ of U.S. nuclear capacity. This success has been achieved with the lowest IPC of all subsidies investigated by this study. These entities are well integrated into the U.S. energy system, have existing capability to accelerate energy technology deployment, and may provide a model for enhancing U.S. efforts to reduce greenhouse gas emissions while sustaining economic growth through domestic investments in low carbon energy infrastructure. In particular, PMA's and rural utilities may provide useful mechanisms for bringing rural renewable electricity to market in a way comparable to their historic role of bringing hydropower and rural electricity to market. Such an effort could provide a useful, low-risk test that can inform future initiatives.

In closing, this study has indicated that IPC is a useful measure in include in analyses of energy incentives and climate policy concepts. IPC should be considered as a standard method for evaluating energy subsidies with regards to climate policy. IPC analyses revealed some areas of specific weakness in U.S. energy policy; and provided insight into how policy could be modified to better achieve climate objectives at reduced cost to the U.S. Treasury. Possible modifications to future U.S. energy subsidies could include (i) inclusion of greenhouse gas reduction objectives in targeted energy subsidies; (ii) greater focus on investment in energy infrastructure rather than incentivized generation; and (iii) looking to historic policy successes within existing governmental organizations when evaluating future options. 


\section{References}

1. U.S. Department of Energy, Federal Financial Interventions and Subsidies in Energy Markets 2007, April 2008, Energy Information Administration, Office of Coal, Nuclear, Electric and Alternative Fuels, Washington, D.C., SR/CNEAF/2008-01

2. Environmental Law Institute, Estimating U.S. Government Subsidies to Energy Sources: 2002-2008, 2009, Environmental Law Institute, Washington, D.C.,

3. Goldberg, M., FEDERAL ENERGY SUBSIDIES: NOT ALL TECHNOLOGIES ARE CREATED EQUAL, 2000, Renewable Energy Policy Project, Washington, D.C.,

4. United Nations Environment Programme, Reforming Energy Subsidies, Opportunities to Contribute to the Climate Change Agenda, 2008, Division of Technology, Industry, and Economics,

5. Energy Information Agency, Electric Power Monthly with data for September 2009, 2009, U.S. Department of Energy, Washington D.C., DOE/EIA-0226 (2009/12)

6. Bartlett, D.L., J.B. Steele, and L. Karmatz, The Great Energy Scam, in TIme Magazine. October 2003, Time Warner Inc.

7. Creyts, J., et al., Reducing U.S. Greenhouse Gas Emissions: How Much at What Cost, 2007, McKinsey \& Company, U.S. Greenhouse Gas Abatement Mapping Initiative, Washington, D.C.,

8. Burnham, A. and Y. Wu, Development and Applications of GREET 2.7 - The Transportation Vehicle-Cycle Model, 2006, Argonne National Laboratory, Argonne, IL, ANL/ESD/06-5

9. $\quad$ Farrell, A.E. and D. Sperling, A Low-Carbon Fuel Standard for California Part 1: Technical Analysis, 2007, University of California at Davis, Institute of Transportation Studies, Davis, CA, UCD-ITS-RR-07-07

10. Hill, J., et al., Climate change and health costs of air emissions from biofuels and gasoline. PNAS, 2009. 106(6): p. 2077-2082.

11. INFRAS, et al., Cost-effectiveness of Greenhouse Gases Emissions Reductions in Various Sectors: Final Report, 2006, EC - DG Enterprise and Industry,, Zurich/Bern, Framework Service Contract No Entr/05/18

12. SEPA, SEPA 2009 Annual Report, 2009, Elberton, CA,

13. TVA, TVA Form 10-K, 2009, U.S.S.a.E. Commission, Washington, DC,

14. SWPA, 2007 Annual Report, SOuthwestern Power Association, 2007, Washington, DC,

15. WAPA, Western Area Power Administration FY2008 Annual Report, 2008, Washington, DC,

16. BPA, 2008 BPA Facts, 2008, Bonneville Power Association, Washington, DC,

17. Tremblay, A., et al., eds. Greenhouse Gas Emissions: Fluxes and Processes, Hydrolectric Reservoirs and Natural Environments. Environmental Science. 2005, Springer: New York. 732. 


\section{Appendix I - Summary of Policies Assessed in Case Studies}

\section{Case 1-Fuel specific subsidies to electricity generation}

1. Refined coal (1 subsidy).

- $\quad$ Alternative Fuel Production Credit. \$2,370 million in FY 2007. Established in 1980 in PL 96-223. Originally intended for coal-bed methane (CBM). CBM credit expired in 2002. Refined coal, defined in Section 710 of PL 108-357, is now largest beneficiary.

2. Non-refined coal (5 subsidies).

- $\quad$ Capital gains treatment of royalties in coal. \$170 million in FY 2007.

Established in 1951 (PL 82-183, Sect. 177j-k). Coal royalties to owners of coal mining rights who lease property are taxed at a lower individual capital gains rate rather than the higher top rate.

- $\quad$ Partial Expensing for advanced mine safety equipment. \$10 million in FY 2007. Established in 2006 (PL 109-432). Allows qualified mine safety equipment to be expensed rather than capitalized.

- $\quad$ Exclusion of special benefits for disabled coal miners. \$40 million in FY 2007. Established in 1986 (PL 99-178) allows for payment of medical-related travel expenses. Payments to miners out of the Black Lung Trust Fund are excluded from taxable income.

- $\quad$ Credit for investment in clean coal facilities. \$30 million in FY 2007. Established in EPACT05 (Section 1307). 20\% credit applied to IGCC, 15\% credit to other technologies. Capped at $\$ 1.3 \mathrm{~B}$, with $\$ 800 \mathrm{M}$ to electricity IGCC and $\$ 350 \mathrm{M}$ to industry gasification.

- $\quad$ 84-month amortization of certain pollution control facilities. $\$ 30$ million in FY 2007. Established in EPACT05 (Sect. 1309). Extends amortization period for qualifying pollution control facilities added to plants built before 1976 from 60 month to 84 months, and extends applicability to plants put in place after 11April, 2005.

3. Nuclear (1 subsidy).

- $\quad$ Modification of special rules for Nuclear Decommissioning. \$199 million in FY 2007. Established in EPACT05 (Sect. 1310). Repeals cost-of-service requirement for contributions to a qualified decommissioning trust fund. EIA treats it as a subsidy to nuclear fuel.

4. Renewable (3 subsidies).

- New Technology Credit. \$690 million in FY 2007. Estabished in 1978 (PL 95618 ) as a $10 \%$ tax credit for solar, wind, geothermal, and ocean-thermal. Also known as the production tax credit (PTC). In FY 1993, the PTC was 1.5 cents $/ \mathrm{kWh}(1.9$ cents/ $\mathrm{kwH}$ in 2006). Credit is available for $10 \mathrm{yrs}$, with the receiver able to defer receipts. Qualified facilities must have been placed in service between 1994 and 2001. 
- $\quad$ Credit for holding clean, renewable energy bonds (CREBs). \$60 million in FY 2007. Expanded in EPACT05 (Sect. 1303). Investor owned utilities and non-IOU electricity providers can issue "clean renewable energy bonds" (CREBs) through 1-Dec., 2008. Taxpayers holding CREBs are entitled a tax credit in lieu of interest payments from the bond issuer. Currently capped at $\$ 1.2 \mathrm{~B}$.

- $\quad$ Renewable energy production incentive. \$4.7 million in FY 2007. Established in EPACT1992 (Sect. 1212). Provides payments for electricity produced and sold by qualifying new renewable energy generation facilities. Targeted to renewable generation owned by state, local, tribal, and not-for-profit utilities that started operation between OCt-1993 and Sept.-2003. Payments are 1.5 cents/kWh (1993 $\$ \$$ ) for qualifying facilities, for 1 st 10 yrs of operation. Different from PTC in that this is a direct payment rather than a tax credit, and availability of payments is limited to annual appropriations.

\section{Case 2-Support to Renewable Electricity from the New Technology Credit}

Detailed analysis of the New Technology Credit, as discussed above

\section{Case 3-Ethanol and Biodiesel}

1. Volumetric Ethanol Excise Tax (VEETC). \$2,990 million in FY 2007. Established by PL 108-357, the American Jobs Creation Act (AJCA, 2004, Title 3, Sec. 301-302), and was preceded by the alcohol fuels excise tax (Sec. 221 of PL 95-618, 1978). Provides retailers and blenders with $\$ 0.51$ per pure gallon of ethanol blended into motor gasoline (\$0.0051 per percentage point of ethanol in gasoline).

2. Biodiesel and Small Agri-Biodiesel Producer Tax Credit. \$180 million in FY 2007. Established by American Jobs Creation Act (AJCA, 2004, Sec. 313), and extended through 2008 by EPACT05 (Sec. 1344). $\$ 1.00$ per gallon for sale of agri-biodiesel fuel from "virgin" feedstock such as soybeans or cottonseed. $\$ 0.50$ per gallon credit to biodiesel from recycled grease.

\section{Case 4-Federal utilities and electricity support to rural utilities}

Detailed analysis of federal interest rate support to rural utilities and power marketing administrations (PMA's), as reported by EIA (2008, SR/CNEAF/2008-01) and discussed in text. 


\section{Appendix II - Greenhouse Gas Emissions for Case Studies}

\section{Case 1-Fuel specific subsidies to electricity generation}

1. Refined coal. Emissions treated the same as for non-refined coal.

2. Non-refined coal. "Simple" (e.g. direct) emissions of 94.7 million metric tons $\mathrm{CO}_{2}$-eq per quadrillion Btu in 2007 (http://www.eia.doe.gov/environment.html) are typical. Actual emissions data reported to EIA indicate a value of 0.98 metric tons $\mathrm{CO}_{2} \mathrm{e}$ per MWh in 2007.

3. Natural gas. Simple" (e.g. direct) emissions of 53.1 million metric tons $\mathrm{CO}_{2}$-eq per quadrillion Btu in 2007 (http://www.eia.doe.gov/environment.html) are typical. Actual emissions data reported to EIA indicate a value of 0.42 metric tons $\mathrm{CO}_{2} \mathrm{e}$ per MWh.

4. Nuclear. Zero-emissions.

5. Renewable. Total U.S. mix in 2007 estimated as $70 \%$ hydropower, $11 \%$ biomass, $5 \%$ biowaste, $4 \%$ geothermal, $10 \%$ wind and solar. Based on the individual values listed below, this is approximately 0.03 metric tons $\mathrm{CO}_{2} \mathrm{e}$ per MWh.

- Biowaste. Assume that biowaste electricity is a mix of 50\% municipal solid waste (MSW), 50\% landfill gas (LG).

○ MSW emits 91.9 pounds $\mathrm{CO}_{2}$-eq per million $\mathrm{Btu}$, assuming energy content of $5,000 \mathrm{Btu} /$ pound and composition that is $84 \%$ biomass (zero-emissions) and $16 \%$ plastics.

- Landfill gas emits 115.26 pounds $\mathrm{CO}_{2}$-eq per million Btu, same energy content as natural gas.

○ $\quad$ EIA reference $=$ http://www.eia.doe.gov/oiaf/1605/coefficients.html

- No data is available for emissions per $\mathrm{kWh}$, so emissions factor per $\mathrm{kWh}$ for MSW and landfill gas is estimated from that of natural gas using the following equations:

- LG per $\mathrm{kWh}=\mathrm{NG}$ per $\mathrm{kWh} *$ (LG per quad / NG per quad)

- MSW per kWh $=$ NG per kWh * (MSW per quad / NG per quad)

○ By this estimate, biowaste electricity emissions equate to approximately 0.42 metric tons $\mathrm{CO}_{2} \mathrm{e}$ per MWh.

- Geothermal. EIA (2008), "Geothermal Energy - Energy from the Earth's Core" estimates that geothermal emits less than $1 \%$ of the GHG's per MWh of a coal plant. Estimate emissions as $0.01 *$ coal emissions factor. This equates to 0.01 metric tons $\mathrm{CO}_{2}$ e per MWh.

- Hydropower. In Table 26.2 of their book (referenced below), Tremblay et. al. [17] estimate that average boreal hydropower reservoirs emit $\sim 15 \mathrm{~g} \mathrm{CO}_{2}$-eq per $\mathrm{kWh}(\mathrm{e})$. This equates to 0.015 metric tons $\mathrm{CO}_{2} \mathrm{e}$ per $\mathrm{MWh}$.

- There is significant variability in the emissions over both geographic location and age of reservoir, tropical reservoirs can be much higher, and there is controversy with regards to any estimates. 
- $\quad$ All others (wind, solar, biomass). Zero-emissions

6. U.S. grid average electricity. Emissions factor defined as total emissions in 2007 (as reported by EPA) divided by total electrical production as reported by EIA. This equates to approximately 0.59 metric tons $\mathrm{CO}_{2} \mathrm{e}$ per MWh in 2007 .

\section{Case 2-Support to Renewable Electricity from the New Technology Credit}

"Simple" (e.g. direct) emissions as listed above.

\section{Case 3-Ethanol and Biodiesel}

1. Ethanol. Subsidized fuel for VEETC. Lifecycle emissions values from the GREET model, as reported by Farrell \& Sperling, [9]. Values are:

- Midwestern-corn, coal-fired mill. 114 grams $\mathrm{CO}_{2}$-eq per MJ (120.2 million metric tons $\mathrm{CO}_{2}$-eq per quad)

- Midwestern-corn, natural gas fired mill. 70 grams $\mathrm{CO}_{2}$-eq per $\mathrm{MJ}$ (73.8 million metric tons $\mathrm{CO}_{2}$-eq per quad)

- Midwestern-corn, stover-fired mill. 47 grams $\mathrm{CO}_{2}$-eq per MJ (49.6 million metric tons $\mathrm{CO}_{2}$-eq per quad)

- Cellulosic ethanol, prairie grass. 7 grams $\mathrm{CO}_{2}$-eq per $\mathrm{MJ}$ (7.4 million metric tons $\mathrm{CO}_{2}$-eq per quad)

2. Biodiesel. Subsidized fuel for Biodiesel and Small Agri-Biodiesel Producer Tax Credit. Lifecycle emissions values from two sources.

- FAME biodiesel from Midwest soybeans, as reported by Farrell \& Sperling, 2007 [9]. 30 grams $\mathrm{CO}_{2}$-eq per $\mathrm{MJ}$ (31.6 million metric tons $\mathrm{CO}_{2}$-eq per quad)

- FAME biodiesel from Midwest soybeans, as reported by Hill et. al. [10]. 43.8 grams $\mathrm{CO}_{2}$-eq per MJ (46.2 million metric tons $\mathrm{CO}_{2}$-eq per quad)

3. Ultra-low sulfur diesel. "Replacement" fuel for biodiesel. Lifecycle emissions value of 71 grams $\mathrm{CO}_{2}$-eq per $\mathrm{MJ}$ (74.9 million metric tons $\mathrm{CO}_{2}$-eq per quad) from the GREET model, as reported by Farrell \& Sperling [9].

4. California-grade gasoline. Replacement" fuel for ethanol. Lifecycle emissions value of 92 grams $\mathrm{CO}_{2}$-eq per $\mathrm{MJ}$ (97.05 million metric tons $\mathrm{CO}_{2}$-eq per quad) from the GREET model, as reported by Farrell \& Sperling [9].

\section{Case 4-Federal utilities and electricity support to rural utilities}

Electricity emissions profiles as per case \#1. 


\section{Appendix III - Data Inputs for Case Studies}

\section{Case 1-Data used to calculate IPC for fuel specific subsidies to electricity generation}

1. Subsidy value - As per row 7 of Table 1 .

2. Emissions from replacement energy - Values in row 6 of table 1 multiplied by the emissions factors (for replacement energy) provided in Appendix II.

3. Emissions from subsidized energy - Values in row 6 of table 1 multiplied by the emissions factors (for subsidized energy) provided in Appendix II.

All calculations here compared total subsidy value in millions of nominal dollars to total "simple" emissions assuming the switches specified in Table 1.

\section{Case 2-Data used to calculate IPC for support to renewable electricity from the New Technology Credit}

1. Subsidy value - Two cases:

- For annual basis, as per row 9 of Table 2.

- For lifetime basis, annual values in row 9 of Table 2 multiplied by the lifetime of the subsidy provided in Table 3 .

2. Emissions from replacement energy - Two cases:

- For annual basis, calculated per MWh using the emissions factors provided in Appendix II assuming one year of emissions savings for one year of subsidy.

- For lifetime basis, calculated per MWh using the emissions factors provided in Appendix II assuming emissions savings for the project lifetime given in Table 3 for a multi-year subsidy (Table 3).

3. Emissions from subsidized energy - Two cases:

- For annual basis, calculated per MWh using the emissions factors provided in Appendix II assuming one year of emissions savings for one year of subsidy.

- For lifetime basis, calculated per MWh using the emissions factors provided in Appendix II assuming emissions savings for the project lifetime given in Table 3 for a multi-year subsidy (Table 3).

All calculations here compared subsidy per unit energy assuming the switches specified in Tables 2-3. All subsidies are as specified in the New Technology Credit 


\section{Case 3-Ethanol and biodiesel}

1. Subsidy value - $\$ 0.51$ per gallon ethanol, $\$ 1.00$ per gallon biodiesel.

2. Emissions from replacement energy - Two cases, both calculated from the subsidy value per unit energy:

- For ethanol, replacement energy is California grade gasoline with emissions factors as provided in Appendix II.

- For biodiesel, replacement energy is ultra-low sulfur diesel with emissions factors as provided in Appendix II.

3. Emissions from subsidized energy - Six cases (4 ethanol, two biodiesel), all calculated from the subsidy value per unit energy:

- For ethanol, subsidized energy is corn ethanol produced from either coal-, gas-, or biomass- fired mills; or cellulosic ethanol. Emissions factors are as provided in Appendix II.

- For biodiesel, subsidized energy is biodiesel produced from Midwestern soy using one of the two available estimates for lifecycle emissions cost. Emissions factors are as provided in Appendix II..

All calculations here compared total subsidy value in millions of nominal dollars to total "simple" emissions assuming the switches specified in Table 4.

\section{Case 4-Federal utilities and electricity support to rural utilities}

Subsidy values and total generation are as presented in Table 5. Emissions factors are as described for Case \#1 and Case \#2. 


\section{Appendix IV - Climate Change Technology Program, Static Implied Price Calculator; Concept and Deployment (Version 1: March 2010)}

Note - In the time period between development of version 1 of the static IPC calculator (as described in this manual) and the preparation of the preceding report; the calculator has been updated with additional capabilities that enable the user to specify the lifecycle carbon cost of transportation fuels. These capabilities were used in the preparation of the preceding reportbut have not yet been incorporated into the user guide (below). These additions enable additional user-input and do not alter the basic functionality.

\section{PuRpose}

The purpose of the static implied price calculator (IPC) is to provide U.S. Department of Energy, Climate Change Technology Program (CCTP) personnel with a desktop tool that will provide a "first look" at the climate implications of proposed policy without having to request policy scenarios from more comprehensive energy modeling software.

\section{Analytical Approach}

This calculator provides a way to rapidly assess opportunities for developing targeted (microeconomic) policies that yield the greatest reduction in greenhouse gas (GHG) emissions per dollar of public subsidy. This assessment is done in terms of the implied price of carbon from federal policies, which is defined as the value of a federal subsidy divided by the greenhouse gas emissions avoided as a result of that subsidy. Values with a lower price are more cost-effective at reducing emissions, so long as that price is greater than 0 . Negative prices either (i) reduce GHG emissions while reducing costs, or (ii) effectively pay to increase GHG emissions. These two effects can be distinguished on the basis of policy cost per unit energy produced and total emissions reductions.

The calculator uses a combination of user-assumptions and EIA data as inputs, and estimates what the IPC of a policy would be if it were perfectly effective, and every dollar of incentive produces the assumed switch in energy resource use and associated emissions changes. This analysis ignores the dynamics of price and demand and does not account for the levelized cost of energy production (LCOE). To reiterate, this calculator provides CCTP with enhanced capability to develop "ballpark estimates" of policy impacts that can be used to rapidly "check" ideas, prioritize future analyses, and help frame the scope of investigation for those analyses. It is solely intended to augment standard modeling procedures so that such efforts can yield an improved return on investment. The static IPC calculator provides a tool to assess current and potential microeconomic incentives on the basis of their impacts on identified climate change priorities. The calculator only applies to federal policies, and provides information on the following parameters:

- Policy cost per unit energy produced.

- Total emissions reductions.

- Implied price of carbon (IPC). 
The calculator is not a model. It is intended to support policy calculations needed to effectively frame and prioritize subsequent (more detailed) studies. It provides the continuity and transparency needed to make the results of calculations that involve large databases and numerous simplifying assumptions both trustworthy and useful. The calculator allows users to replicate the calculations with updated data, assess the merits of assumptions, and more easily discover why different assessments using different bases may yield different results.

\section{Key Assumptions}

The calculator is predicated upon a number of assumptions. Some of these apply across all calculations, while others apply to a specific calculation or set of calculations. This section discusses only the broader assumptions. Assumptions that have a narrower impact are presented and discussed in comment boxes within the calculator (Excel spreadsheet). In approximate order of importance, the broad assumptions are:

1. Static, equilibrium system - The calculator assumes no impact of price curves for energy generation on the implied price of carbon (IPC) from a policy. The energy switches are exactly as specified by the user.

2. Perfectly effective policies - The calculator assumes that the specified policy is perfectly effective, and every dollar of incentive produces exactly the change in energy resource use (and associated emissions) that is specified by the user.

3. Policies evaluated in the context of their impact on energy services- Most targeted policies functionally act to provide an incentive on the use of a resource. However, the value of the resource is in the service that it provides. To accommodate this, the calculator organizes subsidies around the type of service that they support. If a single resource supports multiple services (e.g. coal, natural gas), then the calculator only addresses the portion of the resource dedicated to that service. This is done through parsing of EIA data to approximate how energy from different resources flows to these services. The parsing is documented in the spreadsheet. The parsing in version 1 of the IPC calculator is not as exacting as for the energy flow diagrams produced by LLNL. The update for version 2 will apply the LLNL parsing method to the IPC calculator.

4. Except for transportation fuels, emissions factors for direct emissions as reported by DOEEIA-The calculator utilizes direct emissions data reported by the U.S. DOE Energy Information Agency, which reports emissions as per IPCC practices.

5. For transportation fuels, lifecycle emissions from the GREET model [8]_ Uses values from the GREET model for fuels that are assumed to be generally representative of fuels currently in use. The representative fuel is noted in comments within the calculator. There is a capability to project future changes in lifecycle emissions, though it is difficult to use in the current version.

6. GHG emissions estimated from the amount of fuel used, the energy content of the fuel used, and the GHG emissions factor for that fuel - Subsidies impact fuel use, and thus we calculate associated emissions from fuel use and the emissions factor for that fuel.

- Use of resource $=$ as reported and/or projected by EIA for the fuel specified by the user in the units specified. User can set what percentage of total production is impacted by the subsidy. 
- Energy from resource $(\mathrm{MWh}$ or quads $)=$ One of two definitions.

○ Renewable electricity $=$ MWh as specified

- All other $=$ Resource use (mass units) * energy per unit mass

- Emissions (million mtons $\mathrm{CO} 2$-eq $)=$ Energy generated $* \mathrm{CO} 2$ per unit energy

7. Real dollars calculated by GDP deflator series with 2000 as the base year-Conversions from nominal dollars to real dollars are done using the GDP deflator series as reported in Table 10.1 of the 2009 U.S. Budget (US GPO). This series contains different values than that used by EIA in some of their reports, and can produce significant discrepancies.

The calculator evaluates policies from a direct emissions perspective, with the exception of transportation fuels, which are evaluated from a lifecycle emissions perspective. That is, the services they provide rather than direct resource use. It is important that energy resources are treated consistently across multiple services (e.g. electricity, heating, transportation fuels). This is problematic for transportation fuels, because the fuel itself is only an intermediate service that requires emissions to produce - but does not emit itself until it is used to move a vehicle. Thus, the energy service of transportation fuels has both actual emissions (associated with supplying the service) and implied emissions (associated with service use) while the energy services of electricity production and heating have only actual emissions.

To account for this, we are using lifecycle values from the GREET model to calculate the implied price of carbon for transportation fuels but direct values for to calculate the price for electricity and heating. This creates a small inconsistency. The calculator accounts for only the emissions associated with resource use for electricity and heat; but accounts for all emissions associated with extracting raw resources, transporting them to refineries, converting resources into fuels, transporting fuels to the end user, and using transportation fuels. However, the sum of fuel production and fuel combustion typically accounts for approximately $90 \%$ of total emissions in lifecycle calculations ( $\sim 80 \%$ for combustion alone). While noteworthy, this degree of error is of secondary importance relative to the impacts of the other simplifying assumptions embodied within this calculator. This inconsistency can be addressed by adding a function that allows the user to specify the lifecycle emissions value of fuels, or select from a menu of options based the GREET model. We plan to add this function in version 2 of the IPC calculator.

\section{Data Resources}

The calculator largely uses published EIA historical data as inputs for energy use. It also contains the latest projections on energy use, as reported in the Annual Energy Outlook. The current projections are limited to the year 2012, as that is the latest year for which there are projections for both energy use and energy policy costs. Projections to 2030 are available from EIA, but it is unclear if they would additional value.

The calculator uses GREET model lifecycle emissions data and EIA emissions factors as discussed before. There are a number of specific cases where neither EIA nor GREET provide useful data on emissions. For these cases, the best available information was gathered from the 
literature and commented in the calculator. One particularly noteworthy example is in estimating the greenhouse gas emissions associated with conventional hydropower electricity. Hydropower reservoirs inundate large areas, resulting in a net increase in greenhouse gas flux. EIA does not report this information. HydroQuebec has done an extensive study on this issue (http://www.hydroquebec.com/sustainable-development/documentation/ges.html), and provides a good summary of the literature on greenhouse gas emissions for different energy options. There is significant controversy in the literature, and the GHG emissions from reservoirs are dependent on a number of factors - including reservoir size, climate zone, reservoir age, and local environmental factors. Based on a review by Tremblay et al.[17], we have adopted a value of $15 \mathrm{~g} \mathrm{CO} 2$-eq per kilowatt hour electric as being representative of North American hydropower reservoirs. Note that this is a "Full Energy Chain" GHG emissions factor value rather than a direct value, and is somewhat inconsistent with the calculator's approach of using direct emissions factors. However, given the variability of hydropower resources, the degree of bias in using a lifecycle value is likely much less than the degree of error from assuming an average value for all hydropower. This issue could be addressed in a future version of the calculator, but it is unclear if that would provide significant added value. There are similar issues in estimating the greenhouse gas emissions associated with "minor" renewable sources such as geothermal energy, landfill gas, and combustion of municipal solid waste. As with hydropower, we have detailed our assumptions in the calculator and note that greater user-flexibility in specifying parameters could be achieved if desired.

\section{INSTRUCTIONS FOR USE}

This section provides instructions for how to use the static IPC calculator. These instructions assume a working familiarity with Excel, including familiarity with the use of the Excel chart tool. As such, we provide general instructions, and depend upon the user's knowledge of Excel to apply these instructions to specific cases. The instructions refer to the provided flowcharts. Note that the user should only insert data into the yellow-highlighted cells. Anything not in a yellow-highlighted cell is automatically calculated.

\section{Step \#1 - Specify energy impacts of subsidy}

First, specify the energy switch that the subsidy is intended to stimulate. To do this, follow the logic flow in the chart below. Selections are made either via manual entries or drop-down lists encoded in the calculator. To make a selection:

1. Navigate to the spreadsheet page titled "Input Parameters Here" (bottom tabs).

2. If selecting from a list, then:

- Click on the yellow cell next to the instruction box.

- Click once on the arrow icon.

○ Highlight the energy service or resource(s) desired, and click.

3. Otherwise (no drop-down list), enter a numerical value in the yellow box. 
Flowchart 1- Specify Energy Impacts of Subsidy

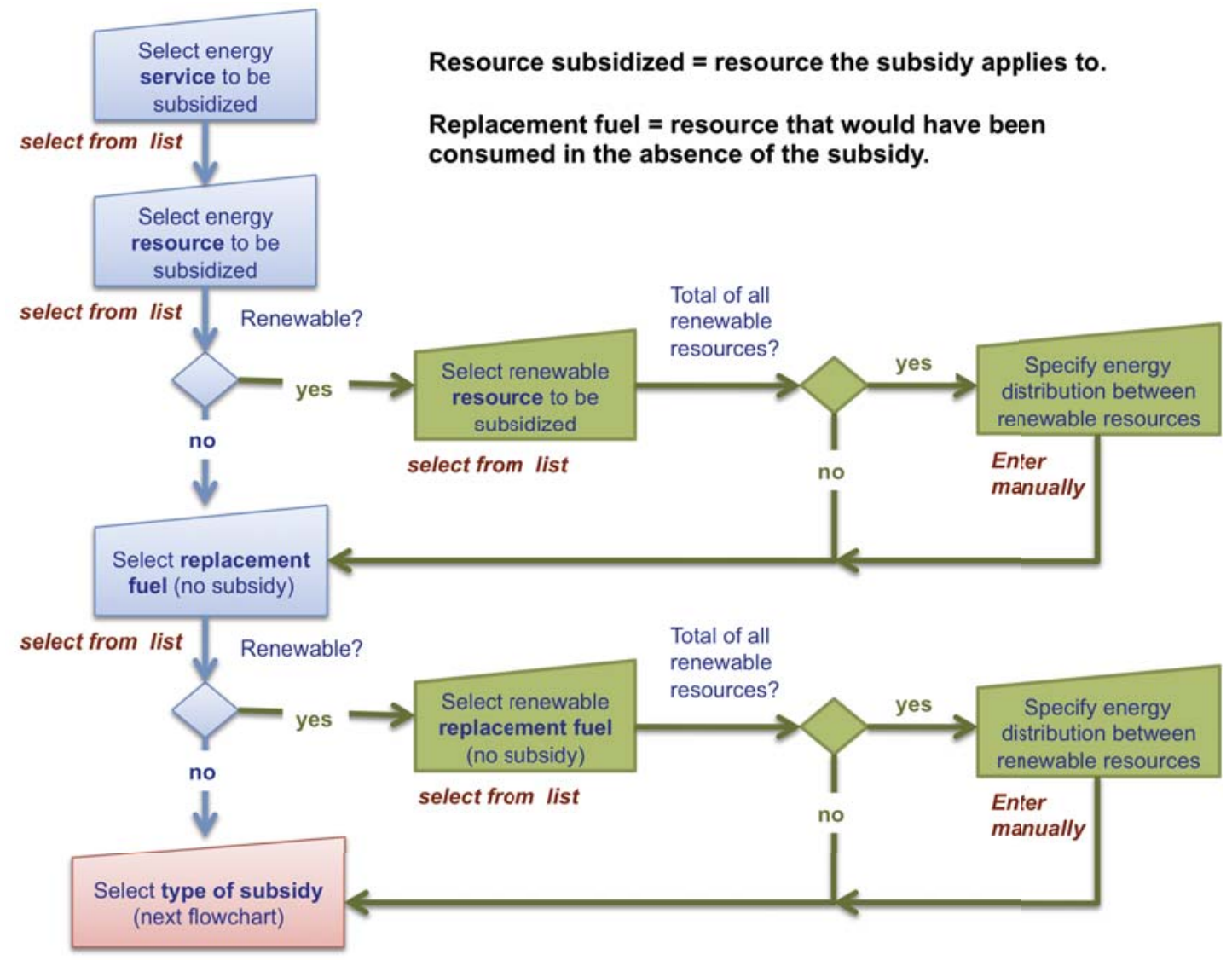

Once these selections are made, the calculator will exchange the energy associated with the subsidized resource on a per-unit-energy basis (e.g. MWh, quads) with that associated with the replacement fuel. This exchange defines the GHG emissions difference between the subsidy and replacement fuel.

There are three key assumptions the user needs to be aware of at this stage. First, the calculator assumes that energy demand will be the same as summarized in historic EIA data and/or projected by EIA in the Annual Energy Outlook. The total energy usage used will be the same, as will the distribution between the different sectors and energy services. The only thing that changes is the energy resource used to support the energy service. Second, the calculator apportions energy resources according to the service they support. For example, selecting electricity and coal will only calculate energy and emissions associated with coal used for electricity generation; and will not account for coal used for industrial or heating applications. In 2008, the approximate distribution of resources between services was;

- Coal- 91\% electricity, 9\% heating and feedstocks, $0 \%$ transportation

- Natural Gas - 30\% electricity, 70\% heating and feedstocks, $0.1 \%$ transportation

- Oil-0\% electricity, 30\% heating and feedstocks, $70 \%$ transportation 
- Nuclear- $100 \%$ electricity

- Non-biomass, non-geothermal renewable - $100 \%$ electricity

- Biomass- $11 \%$ electricity, $68 \%$ heating and feedstocks, $21 \%$ transportation

- Geothermal-88\% electricity, $12 \%$ heating

Third, if the user decides to subsidize or replace-with total renewable resources instead of a specific type of resource, then the calculator requires the user to specify a percent distribution between the component renewable resources. In this case, the calculator's internal assumptions only apply to the total of all renewable resources that support a particular service and not the distribution of specific types of renewable resources. The user provides this information. Note that, used in combination with other features of the calculator, this capability provides considerable flexibility in evaluating potential alternative structures for renewable resources.

The calculator also will allow the user to estimate the IPC of subsidies intended to direct the construction of transmission and pipeline infrastructure towards the use of specific resources. For example, if there were a subsidy intended to support the construction of transmission specifically to access renewable resources. For these, transmission applies to all electricity and pipelines apply to all oil and natural gas. The calculator assumes that coal is transported solely by truck and rail; and that pipelines do not currently transport biofuels.

\section{Step \#2 - Specify subsidy structure (type of subsidy, and how it will be valued)}

The second step is to specify the structure of the subsidy. This is done on the same page and via the same procedures as step \#1. This process is more complex than for step \#1, and requires inputs on two different spreadsheet pages. The easiest way to do this is to follow the logic flow in flowchart 2 (below). As with step \#1, selections are made either via manual entries or using drop-down lists encoded in the calculator. To make a selection:

1. Navigate to the spreadsheet page titled "Input Parameters Here" (bottom tabs).

2. If selecting from a list, then:

a. Click on the yellow cell adjacent to the instruction box.

b. Click once on the arrow icon.

c. Highlight the energy service or resource(s) desired, and click.

3. Otherwise (no drop-down list), enter a numerical value in the yellow box.

The calculator currently supports five types of federal payments. Subsidy type is specified according the logic outline in flowchart 2. Selections made here impact the calculator in several ways, and the requested information should be entered even if it is not apparent why it is needed. The types of federal payments supported and criteria to be specified are:

1. Annual energy production tax credit- Tax credit valued on a per-unit-energy basis, and whose entire cost and impact occurs within a single year.

- Required inputs = subsidy value

- Subsidy can be specified, or estimated. 
2. Annual energy production tax credit linked to the price of oil-As above, but with the value of the credit within a given year linked to the benchmark price of crude oil.

- $\quad$ Required inputs = subsidy value, special inputs for defining both when and how the value of the subsidy is linked to the price of oil.

- Subsidy can be specified, or estimated.

3. Extended energy production tax credit - Tax credit valued on a per-unit-energy basis, and whose entire cost and impact occurs over multiple years.

- $\quad$ Required inputs = subsidy value, special inputs for defining subsidy cost and GHG emissions reductions over an extended time period.

- Subsidy can be specified, or estimated.

4. Investment tax credit - Tax credit linked to the value of a capital investment.

- This function is still being developed. Cannot yet be used.

5. Income tax rate adjustment - Income tax rate adjustment that is not specifically linked to energy production or investment, but impacts energy production in an indirect way.

- $\quad$ Required inputs = subsidy value

- Subsidy can only be specified.

Flowchart 2 - Specify Subsidy Structure (Type and Valuation Method)

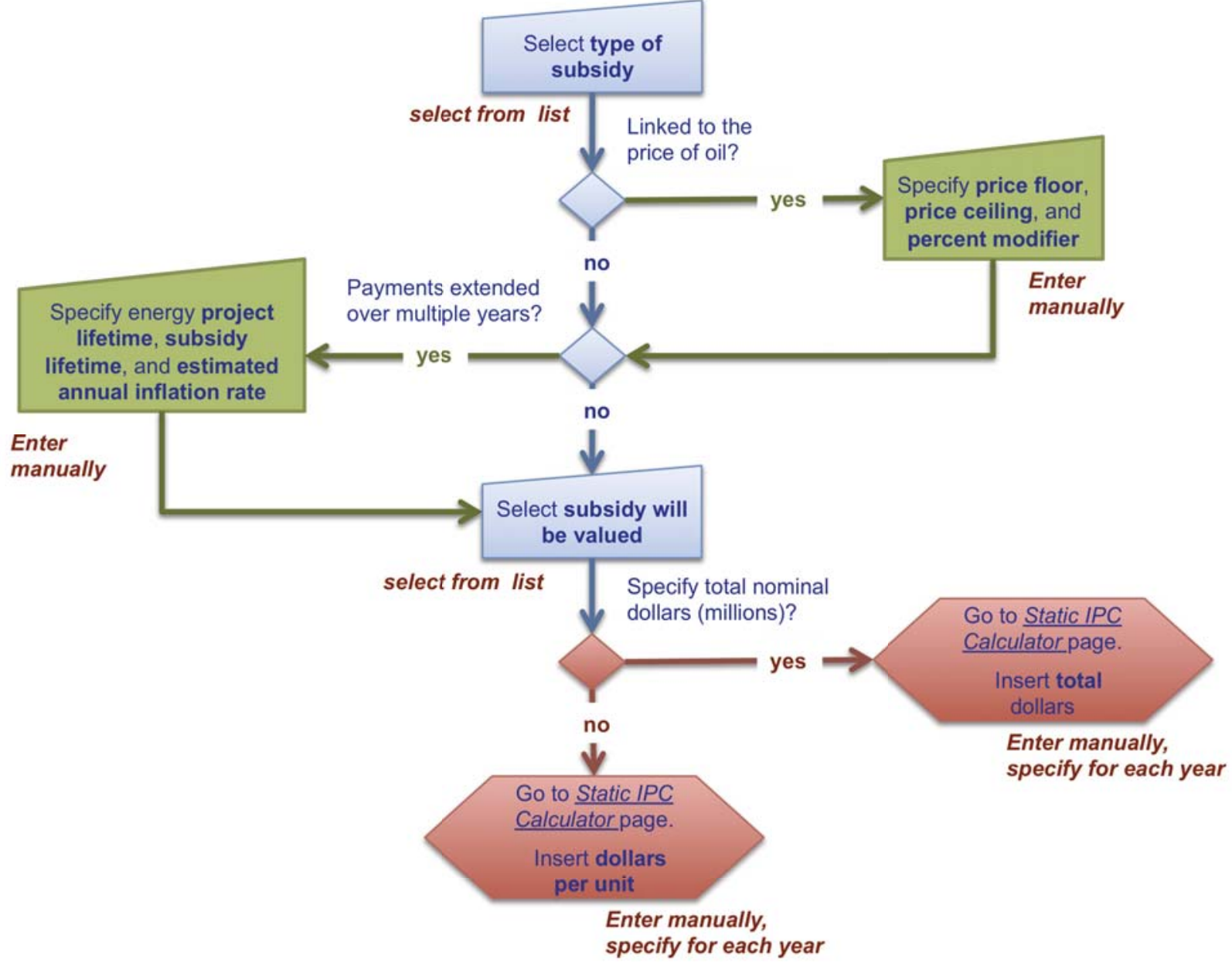


For three of the five subsidy types, the annual value can either be specified by the user or estimated via one of a maximum of four methods. The value of an income tax rate adjustment cannot be estimated. It must be specified. The current version of the calculator cannot estimate the value or emissions impact of an investment tax credit, and this function is currently only a "placeholder". The four methods for estimating the value of a subsidy are:

1. Nominal dollars per unit production - Value of the subsidy is expressed in cost per unit production of the energy resource, in dollars of the day (not adjusted for inflation). Virtually all existing resource-specific production subsidies are valued in this way.

- The production unit varies with energy resource (e.g. barrels, tons, thousand cubic feet, gallons, megawatt hours, quads).

- The production unit that the calculator assumes as the basis for the subsidy is given in the box where the energy resource subsidized is specified.

2. Million nominal dollars per quad of energy content - Value of the subsidy is expressed in cost per unit quad of energy content of the energy resource. This option is not available for resources that produce electricity. No current subsidy functions in this way, but this method may be useful for evaluating how a potential subsidy might work.

3. Nominal dollars per percent reduction in $G H G$ 's from a specific resource- Value of the subsidy is expressed in cost per percent reduction in GHG's from a subsidized resource. No current subsidy functions in this way, but this method may be useful for evaluating how carbon tax might work if applied to a specific type of resource.

4. Nominal dollars per metric ton of GHG reductions from a specific resource- Value of the subsidy is expressed in cost per metric ton reduction from a subsidized resource. No current subsidy functions in this way, but this method may be useful for evaluating how carbon tax might work if applied to a specific type of resource.

General notes on specifying subsidy structure in the static IPC calculator

The calculator has limited capability to estimate how the implied price of carbon (IPC) may vary over time, for a given subsidy structure. This allows the user to determine how the IPC may change if the value of a subsidy increases or decreases over time in real or nominal terms; or if the impact of the subsidy on the market were to grow or shrink. This capability is defined by two inputs on the "Static IPC Calculator" spreadsheet page (yellow boxes, rows 10, 11).

- Row 10, percent of total production of subsidized resource that is supported - User specifies the market penetration of the subsidy. For example, does a production tax credit apply to all energy produced from a given resource in a given year; or only a portion?

- Row 11, value of subsidy in a given year (via method specified) - User specifies the value of the subsidy, for each year, as discussed previously.

The calculator places no limits on the values that the user can place in the yellow boxes in rows 10 and 11 . These can be any value the user wishes, and provide considerable flexibility in evaluating how potential alternative subsidy structures might function in comparison with existing subsidies. 


\section{Example}

In this example, consider how the total cost of a subsidy and its IPC might change if the subsidy was not capped and it successfully increased market penetration. For an example of this, consider the annual cost of the wind production tax credit where, (i) the credit is continuously available since 1999, (ii) $5 \%$ of the market were subsidized in 1999 and then increasing by $10 \%$ per year, and (iii) the wind energy would be replaced by "grid average" electricity in the absence of a subsidy. This case is entered into the calculator as follows:

1. Step \#1-On the parameters input page, make the following selections:

- Service to be subsidized = "Electricity"

- Energy resource supported = "Renewable (multiple units)"

- Renewable resource subsidized = "Wind and solar electricity $(\mathrm{MWh}) "$

- Replacement Fuel = "Grid average electricity $(\mathrm{MWh})$

- Renewable replacement fuel = not applicable

- Type of Subsidy = Annual energy production tax credit (PTC)

2. Step $\# 2 a-$ On the parameters input page, make the following selections:

- $\quad$ Type of Subsidy = Annual energy production tax credit (PTC)

- How subsidy is specified $=$ Nominal dollars per unit production (in this case, dollars per megawatt hour)

3. Step $\# 2 b$ - On the Static IPC Calculator page, make the following entries:

- Percent of production subsidized (row 10) $=5 \%$ in 1999, $10 \%$ increase per year through 2008, 100\% in 2009 and each subsequent year.

- Value of subsidy in nominal dollars per MWh (row 11) $=\$ 19$ in 2006, value corrected for inflation in all other years using the GDP deflator series in row 9 (this deflator series yields a value of $\$ 16 / \mathrm{MWh}$ in 1999).

4. Analyze Results - Results are given on rows $12-17$ of the Static IPC Calculator Page

- Row 12 (red) = implied price of carbon in nominal dollars per metric ton of reduction.

- Rows $13-17$ (green) = other useful information

- Rows $2-6$ (blue) = summary of parameters previously specified

- Rows 18 and above (grey) = intermediate calculation steps

- Important-Do not change values in any square except the yellow ones!

The results from this hypothetical case indicate that the IPC would range from $\$ 27$-- $\$ 34$ per metric ton (nominal dollars) while the total cost of the subsidy more than doubles in less than 10 years ( $\$ 300$ million in 1999 , over $\$ 680$ million in 2007 ). In comparison, the actual value of the new production tax credit increased from $\$ 50$ million in 1999 to $\$ 690$ million in 2007. This federal credit covers multiple renewable technologies ( $\sim 90 \%$ going to wind generation), and has lapsed and been reinstated several times.

Note that there is no rule that requires the value of a subsidy to be indexed to inflation; or that the percent of production subsidized be between $0 \%$ and $100 \%$. This is useful because it allows the user to examine cases where a set of policies may increase market production beyond what occurred or is projected to occur. For example, what if a R\&D breakthrough were to reduce the cost of ethanol production to the point where three times as much ethanol were 
produced as is projected - but the subsidy remained the same? In this case, the user could specify that greater than $100 \%$ of the current production of the resource is subsidized - yielding a result that is equivalent to having $100 \%$ of a larger production be subsidized.

Additional guidance for estimating subsidies linked to the price of oil and extended tax credits

This section is only applicable when estimating subsidies. If the total value of the subsidy is specified, then the calculations discussed here are not applicable. The calculator provides a way to estimate subsidy values for two types of subsidies that require further explanation; (i) tax credits linked to the price of oil, and (ii) tax credits that act over an extended time period.

For tax credits linked to the price of oil, the value of the credit varies with the benchmark price of crude oil as reported by EIA. The benchmark price is the price on the first trading day of a calendar year. The calculator handles this case via a three-step process.

1. The base value of the subsidy is calculated exactly the same way as with a standard annual production tax credit.

2. If the benchmark price of crude (as per EIA databases or projections) is below the specified floor price or above the specified ceiling price, then the actual value of this credit is equal to the baseline value.

3. Otherwise, the value of the credit is reduced by an amount equal to (value of the credit)*(benchmark price of oil - floor price)*(percent modifier specified by user). The calculator requires the user to provide the floor and ceiling price in terms of real dollars as in calendar year 2000. If the calculation yields a negative subsidy, then the calculator returns no value. In making the calculation, the calculator automatically converts the value of the tax credit as specified by the user to an equivalent in terms of dollars per barrel oil. This conversion is done by calculating the energy content of the resource subsidized, and then converting that energy content to barrels of oil equivalent.

Some tax credits are structured so that eligible facilities are entitled to receive credits for more than one year, and a multi-year cost and emissions return is anticipated. The calculator treats these special cases as extended production tax credits. For these, the following applies:

- $\quad$ Emissions savings $=$ annual savings * project lifetime

- $\quad$ Cost of subsidy = annual cost * subsidy lifetime

- Cost indexed to the assumed average rate of inflation.

- For purposes of calculating the IPC and other values in the calculator, the subsidy only applies to new generation built within that year and the entire subsidy cost (over subsidy lifetime) is accrued within a single year.

An example of this type of credit is the current wind production tax credit, where a facility is eligible for the credit for 10 years. Since wind does not have a fuel cost and most of the cost in generation is in the capital cost of the wind turbine and transmission lines needed to connect the turbine to the grid, there is no benefit to not generating electricity once the turbine is built. Thus, a qualifying wind turbine can be anticipated to claim the credit for a full 10 years - and the true subsidy cost is 10 years worth of annual production. Furthermore, the effect of this credit is to displace an alternative fuel for the entire lifetime of the wind turbine (typically $25 \mathrm{yrs}$ ). 
Accounting for these factors will yield a different implied price of carbon than a single year calculation (e.g. $10 \mathrm{yrs}$ of payments for $25 \mathrm{yrs}$ of GHG reductions versus $1 \mathrm{yr}$ of payments for 1 yr of GHG reductions).

\section{ANALYZING AND COMPARING RESUlts}

The calculator presents results on three different pages, with each page providing a different perspective and fulfilling a different role. Results for an individual calculation are given on the spreadsheet page titled "Static IPC Calculator". They are:

- Row 12 (red) = implied price of carbon in nominal dollars per metric ton of reduction.

- $\quad$ Rows 13 - 17 (green) = other useful information on subsidies.

- $\quad$ Rows 2-6 (blue) = summary of parameters previously specified.

- $\quad$ Rows 18 and above (grey) = intermediate calculation steps.

Comparisons between the current calculation and a small set of other policies are given in charts and tables on the spreadsheet page titled "IPC Calculator Chart". This page gives 1 table and two charts that compare the results from the current calculation with five other examples.

- For the example calculations - Data is provided from 1999 through 2012, with years where there is insufficient available information left blank.

- For the current calculation - Data is calculated for 1999 through 2012, with years where there is insufficient available information marked as "-_" in the table. This value translates as 0 when the data is plotted on a chart.

Summaries are provided in the table. The topmost chart compares the implied price of carbon for each given subsidy for calendar year 1999 and calendar year 2007. The lower chart provides a time series.

The spreadsheet page titled "Policy Comparison Charts" provides the user with a way to keep a record of all the policies investigated. This page is still under development, and is blank in the current version.

\section{Other useful information}

The calculator provides additional information resources that the user may find helpful. The spreadsheet page titled "Policy Information - Payments" provides a summary of selected federal policies, including the size of the subsidy and a brief description of how it works. The remaining pages provide information on energy production, use, and emissions. 


\section{Planned Future Improvements}

The calculator is a work in progress, and we have identified several improvements that could be made. It is planned to give the user more capability to specify emissions and select different fuel portfolios for transportation. For example, the calculator assumes the current average emissions factor for ethanol - but R\&D could reduce that in the future once cellulose ethanol technology becomes widely commercialized. The current version of the calculator cannot handle this. There are also many options for oil from unconventional resources. This version has focused on trying to build a framework for subsidy structure while using the "bare minimum" emissions data. It would be useful to provide increased ability to evaluate emissions scenarios.

It would also be useful to provide an ability to assess the IPC of efficiency and production standards (e.g. fuel economy, efficiency, portfolio standards) in a simplified way. We have proposed to CCTP to do this.

Another useful addition would be to provide a way to assess the IPC value of subsidies from a fuels perspective rather than a services perspective. Information on energy and emissions can be assembled similarly to the present calculator to help gain insight on federal support based on fuel type. The main output would be an estimate of the "implied price" of carbon as generated by the affected technology/fuel. In this way, the calculator could evaluate federal support using a number of different measures that try to capture several different perspectives.

Implied prices (implied per unit federal support levels) are shown in the final three right-hand columns:

- 'Total Implied price' is the total federal support divided by the total green house gas (GHG) emissions generated by that fuel expressed as in dollars per $\mathrm{CO}_{2}$ equivalent tons.

- 'Implied price-Tax Only' is the tax and direct expenditures portion of federal support divided by the total GHG emissions generated by that fuel expressed as in dollars per $\mathrm{CO}_{2}$ equivalent tons.

- 'Total Federal Support' is total federal financial support divided by the total electrical generation from the specified fuel. This measure is gives perspective on how federal monies are allocated across generating technologies/fuels, regardless of emissions. Since about one quarter of electricity generated in the country does not generate GHGs, this measure can be used to compare federal support for technologies that generate GHGs with those that do not.

\footnotetext{
a We use the term "implied price" loosely here. Technically, an implied price refers to a supply and demand relationship, for which there are none here. In economic terms, what we are measuring should more accurately be described as "implicit per unit federal support level" or something similar.
} 


\section{INFORMATION RESOURCES FOR DATA EMBEDDED WITHIN THE IPC CALCULATOR:}

The IPC calculator incorporates energy, emissions, and subsidy information from multiple resources. The citations for these resources are provided in comment boxes within the Excel spreadsheet, and also provided here for ease of reference. The references here are only data resources for the IPC calculator, and are not formally cited within this report.

U.S. Department of Energy. Annual Energy Outlook 2009 with Projections to 2030. Energy Information Administration, Washington, D.C. DOE/EIA-0383(2009). March, 2009.

U.S. Department of Energy. Annual Energy Review 2008: Chapter 10, Renewable Energy. Energy Information Administration, Washington, D.C. DOE/EIA-0384(2008). 26 June, 2009.

U.S. Department of Energy. Federal Financial Interventions and Subsidies in Energy Markets 1999: Primary Energy. Energy Information Administration, Office of Integrated Analysis and Forecasting. Washington, D.C. SR/OIAF/99-03. September 1999.

U.S. Department of Energy. Federal Financial Interventions and Subsidies in Energy Markets 2007. Energy Information Administration, Office of Coal, Nuclear, Electric and Alternative Fuels. Washington, D.C. SR/CNEAF/2008-01. April 2008.

U.S. Department of Energy. Renewable Energy Annual 2007. Energy Information Administration, Office of Coal, Nuclear, Electric and Alternative Fuels Washington, D.C. (2009). April, 2009.

U.S. Department of Energy. Renewable Energy Annual 2000 with Data for 1999. Energy Information Administration, Office of Coal, Nuclear, Electric and Alternative Fuels Washington, D.C. DOE/EIA-0603(2000). March, 2001.

U.S. Environmental Protection Agency, Office of Atmospheric Programs. Inventory of U.S. Greenhouse Gas Emissions and Sinks: 1990-1999. EPA 236-R-01-001. Washington D.C. April, 2001.

U.S. Environmental Protection Agency, Office of Atmospheric Programs. Inventory of U.S. Greenhouse Gas Emissions and Sinks: 1990-2007. EPA 430-R-09-004. Washington D.C. April, 2009. 